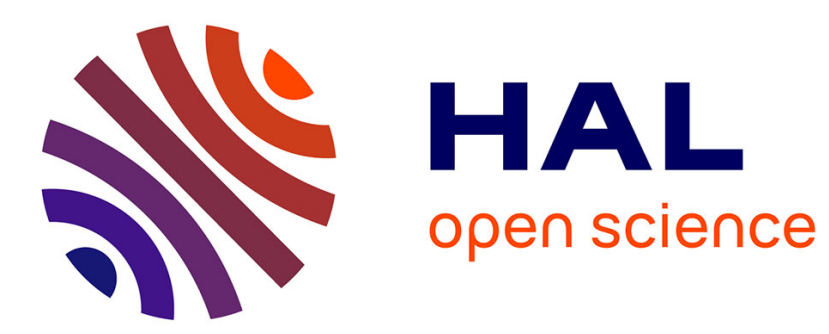

\title{
More facts about prices: France before and during the Great Recession
}

\author{
Nicoletta Berardi, Erwan Gautier, Hervé Le Bihan
}

\section{To cite this version:}

Nicoletta Berardi, Erwan Gautier, Hervé Le Bihan. More facts about prices: France before and during the Great Recession. 2014. hal-01060564

\section{HAL Id: hal-01060564 https://hal.science/hal-01060564}

Preprint submitted on 3 Sep 2014

HAL is a multi-disciplinary open access archive for the deposit and dissemination of scientific research documents, whether they are published or not. The documents may come from teaching and research institutions in France or abroad, or from public or private research centers.
L'archive ouverte pluridisciplinaire HAL, est destinée au dépôt et à la diffusion de documents scientifiques de niveau recherche, publiés ou non, émanant des établissements d'enseignement et de recherche français ou étrangers, des laboratoires publics ou privés. 

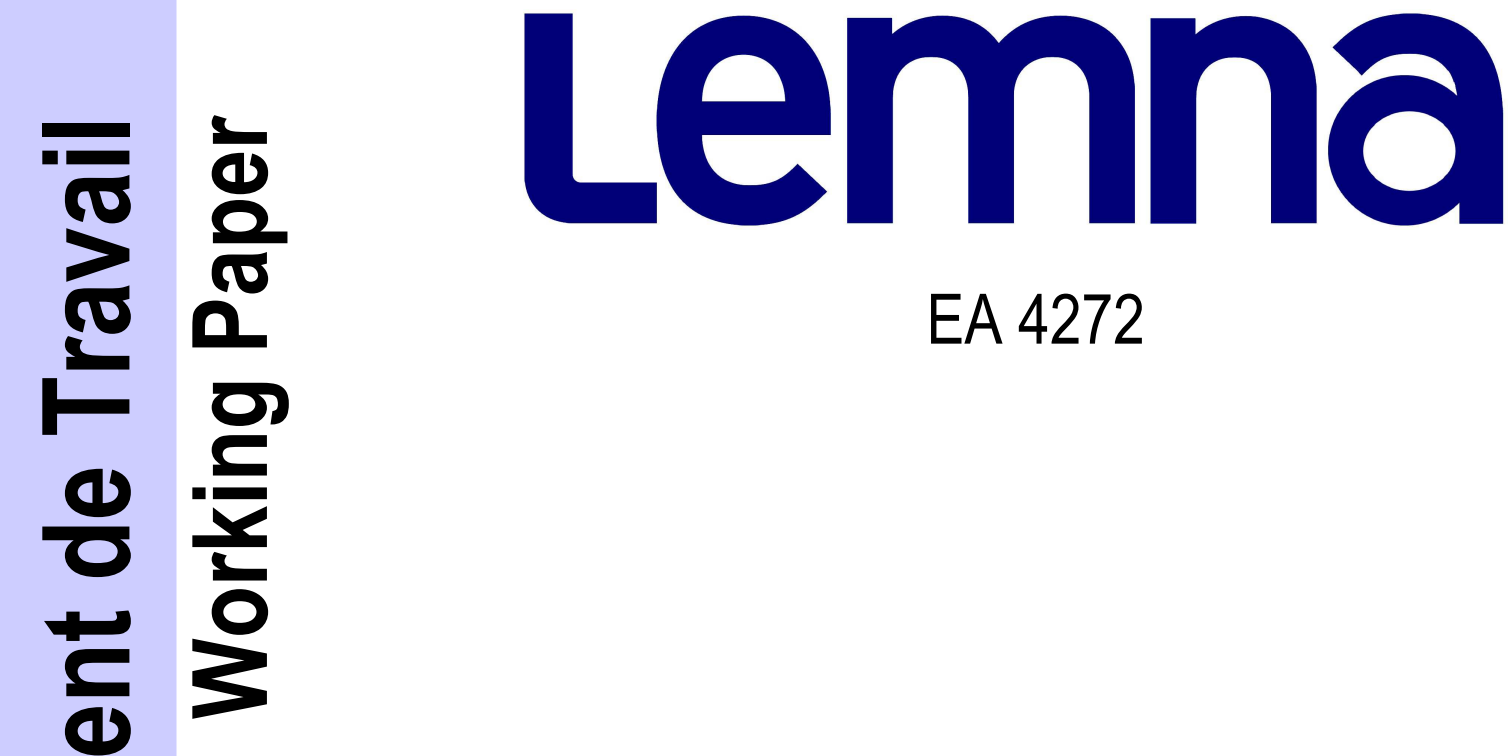

EA 4272

\title{
More facts about prices: France before and during the Great Recession
}

\author{
Nicoletta Berardi* \\ Erwan Gautier** \\ Hervé Le Bihan*
}

$2014 / 21$

$\left.{ }^{*}\right)$ Banque de France

$\left.{ }^{(* *}\right)$ LEMNA - Université de Nantes - TEPP - Banque de France

INSTITUT

d'ECONOMIE

et de MANAGEMENT

de NANTES - IAE

\section{Laboratoire d'Economie et de Management Nantes-Atlantique} Université de Nantes

Chemin de la Censive du Tertre - BP 52231

44322 Nantes cedex 3 - France

www.univ-nantes.fr/iemn-iae/recherche

Tél. +33 (0)2 40141717 - Fax +33 (0)2 40141749 


\title{
More Facts about Prices: \\ France Before and During the Great Recession
}

\author{
Nicoletta BERARDI \\ Banque de France \\ Erwan GAUTIER \\ Université de Nantes - LEMNA - TEPP \\ Banque de France \\ Hervé LE BIHAN \\ Banque de France
}

August 29, 2014

Berardi: nicoletta.berardi@banque-france.fr

Gautier: erwan.gautier@univ-nantes.fr

Le Bihan: herve.lebihan@banque-france.fr

We would like to thank Sylvie Tarrieu for excellent research assistance. We thank the Editor and two anonymous referees for many insightful and useful suggestions. We are also grateful to Olympia Bover, Emmanuel Dhyne, Huw Dixon, Roman Horvath, Francesco Lippi, Emi Nakamura, Julio Rotemberg, Patrick Sevestre, Anya Stockburger and the participants of AFSE congress (Paris, 2012), EEA Congress (Toulouse, 2014), International Conference on Panel Data (Paris, 2012), T2M conference (Lyon, 2013), RES Conference (Manchester, 2014), seminars at Banque de France (Paris, 2012) and Cardiff Business School (Cardiff, 2012) for helpful comments and suggestions. We thank Insee (Direction des Statistiques Démographiques et Sociales) for providing access to the data and, in particular, to Patrick Sillard for discussion and advice. The views expressed in this paper are those of the authors and do not necessarily represent those of Banque de France. 


\begin{abstract}
Using micro price data, we document new facts on price rigidity in France: (i) each month $20.1 \%$ of prices are changed, which compares with $24.1 \%$ in the United States. Excluding sales, however, the fraction of prices modified each month is about the same in France and in the United States (around 17\%); (ii) the distribution of price changes is quite dispersed; (iii) the frequencies of price increases and decreases contribute a lot to inflation variations, and price increases are more frequent in January even when sales are excluded; (iv) sales contribute significantly to the volatility of inflation but are much less sensitive to macroeconomic fluctuations than regular price changes; (v) during the Great Recession patterns of price adjustment were only slightly modified.
\end{abstract}

JEL codes: E31, D40, L11

Keywords: price stickiness, inflation, consumer prices, sales, product substitution 


\section{Introduction}

How prices are set has crucial macroeconomic implications, especially for the real effects of monetary policy or the welfare consequences of business cycles. Over the past decade, a number of empirical studies have provided evidence on micro price rigidity for more than 50 countries. Using price quotes collected for the Consumer Price Index (CPI) calculation, seminal studies by Bils and Klenow [2004], Klenow and Kryvtsov [2008] and Nakamura and Steinsson [2008] have characterized price rigidity for the United States whereas Dhyne et al. [2006] have summarized European evidence. ${ }^{1}$ A recent strand of the US literature has emphasized the relevance of a new set of patterns, such as the shape of the distribution of price changes (in particular its fat tails and the large proportion of small price changes) and the role played by sales and product substitutions in the United States. These patterns have important consequences for the real effects of monetary policy (see for instance, Kehoe and Midrigan [2010] or Nakamura and Steinsson [2010a] for sales, and Costain and Nakov [2011], Golosov and Lucas [2007] or Midrigan [2011] for the distribution of price changes). Our paper adds to the literature on price rigidity along three dimensions. First, we provide new facts on patterns of price rigidity that so far have been little documented for European countries, in particular the impact of sales and product replacements on price rigidity indicators. Second, we provide a detailed comparison of the degree of price rigidity between France and the United States. Finally, we document the impact of the Great Recession on price setting behavior.

For that purpose, we use a new release of CPI price quotes collected in France. Our data set consists of more than 11 million monthly price quotes collected by the national statistical office in order to compute the French CPI, spanning the period from April 2003 to April 2011. This sample allows to extend the evidence with respect to a study by Baudry et al. [2007] covering the period July 1994 to February 2003. Prices are collected for more than 700,000 individual products identified at the outlet level. The sample contains prices for more than 3,500 types of goods and services, allowing the construction of indicators of price rigidity that are representative of the non-farm business economy.

Our first contribution is to provide new findings on price rigidity, with an emphasis on the influence of sales and product substitution-related price changes. Sales were shown to have strong implications for price rigidity in the United States (see for instance Kehoe and Midrigan [2010]). Moreover, a growing recent literature examines the determinants of sales in the United States and their aggregate implications (Anderson et al. [2012],

\footnotetext{
${ }^{1}$ For recent surveys of these findings, see Klenow and Malin [2010], Nakamura and Steinsson [2013] or Smets and Mackowiak [2009].
} 
Coibion et al. [2012], Guimaraes and Sheedy [2011] and Kehoe and Midrigan [2010]). However, little evidence has been made available for European countries. ${ }^{2}$ We find that the frequency of price changes when we exclude sales is $17.4 \%$, versus $20.1 \%$ when they are included. We also obtain that aggregate inflation has a smaller impact on price changes associated with sales than on regular price changes. Considering the distribution of price changes, excluding sales leads to smaller average absolute size, e.g. the average price increase is $7.9 \%$ versus $12.8 \%$. The share of both large and small price changes is large: almost one-fourth of price changes are smaller than $2 \%$ in absolute values in the baseline including-sales data set. Midrigan [2011] shows that those features of the data may have strong implications for the persistence of monetary shocks. Following Klenow and Kryvtsov [2008], we also decompose the monthly fluctuations inflation into an extensive margin (frequency of price changes) and an intensive margin (size of price changes); a substantial fraction of inflation volatility at the monthly frequency is due to sales. When sales are excluded, the frequencies of price increases and decreases are the most important contributions to inflation. In particular, when we exclude sales and promotional discounts, there is still a peak in inflation in January; this peak is mostly explained by an increase in the frequency of price increases (especially in services).

The importance of product substitutions has been stressed in a recent contribution by Nakamura and Steinsson [2008], who argue that product replacements provide an opportunity for changing prices. Our baseline price rigidity indicators assume that price changes observed at the time of product substitutions are genuine price changes. Incorporating product substitution-related price changes contributes positively to the frequency and the average absolute size of price changes: the frequency, equal to $20.1 \%$ in the baseline data set, drops to $17.7 \%$ when disregarding substitutions. The average absolute size is $8.9 \%$ without substitutions versus $12.1 \%$ when including them. Overall, substitutions have a positive impact on average monthly inflation rate, and are needed to match the average inflation rate, although they only slightly contribute to the fluctuations of inflation.

Our second contribution is to run a detailed comparison of the degree of price rigidity between France and the United States. We construct a bridge table to match European and US classifications of products, we identify products that are available in both French and US micro price data sets and we control for differences in CPI weight structures between France and the United States. On the common sample of products, when sales

\footnotetext{
${ }^{2}$ In some countries like Germany, Italy or Spain, sales prices were not available in micro data sets (see Dhyne et al. [2006]). Baudry et al. [2007] provide some results on the frequency of price changes excluding sales as robustness checks.
} 
are included, the frequency of price changes is higher in the United States $(24.1 \%)$ than in France (20.1\%). However, when sales are excluded, the difference vanishes: $17.4 \%$ of price changes in France versus $17.1 \%$ in the United States. Similarly, the average size of price changes is larger in the United States than in France $(14.9 \%$ versus $10.0 \%$ for price increases and $-18.5 \%$ versus $-13.4 \%$ for price decreases) but when sales are excluded the difference drops substantially: the average size of price increases (respectively decreases) is about 6\% (respectively $-9 \%$ ) in France versus $9 \%$ (respectively $-12 \%$ ) in the United States.

Our last contribution is to document micro price setting behavior during the Great Recession. Most existing empirical results on price rigidity were obtained on data collected in the 90s or in this first years of 2000s, a period of stable GDP growth and inflation in Europe and in the United States. However, patterns of price rigidity may be different in a more unstable economic environment. ${ }^{3}$ During the recent Great Recession, GDP growth dramatically decreased whereas inflation variations were mainly due to increasing then decreasing energy prices and core inflation remained rather stable ([ECB, 2012]). To our knowledge, little is known about micro price setting features during that period especially in European countries. ${ }^{4}$ We find that the broad patterns of price adjustment remained mainly unchanged during the recent crisis, which sheds some light on the relative inflation stability during the Great Recession. We show that the Great Recession had a significant positive but small impact on both the frequency and the absolute size of price changes. We also find that the variance of price increases increased somewhat during the Great Recession, which may reflect the larger variance of economic shocks.

The paper is organized as follows. A description of the data is provided in section 2. Section 3 provides cross-sectional evidence on the frequency and size of price changes. We also document the influence on price rigidity of removing sales, and of considering product substitutions as ends of price trajectories or not. We analyze the patterns of the distribution of price changes. We compare our findings with US results. Section 4 presents time-series evidence on the frequency and size of price changes and investigates the impact of the Great Recession on price rigidity indicators. We also explore the impact of sales and product substitution on the fluctuations of the monthly inflation rate. Finally, we provide detailed evidence on the seasonality of price changes and the contribution of sales to this seasonality. Section 5 concludes by summarizing our main results and discussing some of their macroeconomic implications.

\footnotetext{
${ }^{3}$ Gagnon [2009] on Mexican data during the peso devaluation or Wulfsberg [2010] on Norwegian data during the 70s provide evidence on price setting features in unstable economic environments.

${ }^{4}$ Berger and Vavra [2012] and Dixon et al. [2014] document some findings on price distributions during recessions in the United States and the United Kingdom respectively.
} 


\section{Data}

The data are taken from a longitudinal data set of monthly price quotes collected by the Institut National de la Statistique et des Études Économiques (INSEE) in order to compute the French CPI. ${ }^{5}$

\section{$2.1 \quad$ Price quotes}

The sample contains monthly CPI records from April 2003 to April 2011 and each record is related to a precisely defined product sold in a particular outlet. The raw data set contains more than 11 million price quotes and covers about $65 \%$ of the CPI weights. ${ }^{6}$ Those data contain prices for more than 3,500 goods and services, sold in more than 30,000 outlets in more than 100 locations. This large coverage of our data set allows us to calculate indicators of price rigidity that are representative of the non-farm business economy. We aggregate product categories into four sectors: food, manufacturing goods (durables, clothing, and other manufacturing goods), energy, and services.

To extend the sample in our time-series exercises, and for comparison purpose, we also rely on results from an earlier data set, analyzed Baudry et al. [2007], spanning from July 1994 to February 2003. However, because that earlier data set contains less information on product substitutions and the two data sets do not overlap, we are not able to pool the two data sets for our baseline micro level analysis.

For each individual price quote (i.e. the exact price level of the product) the year and month of the record, as well as the type of price record (e.g. sale price) are reported. It is possible to track the price variation of an individual product (i.e. a particular product of a particular brand and quality, sold in a particular outlet) using a single identification number. The sequence of records corresponding to one individual product is called price trajectory. The individual products are characterized by the packaging quantity ${ }^{7}$, the category of product, the outlet where it is sold and its type (e.g. supermarket, traditional store, etc). In our basic analysis, price changes are computed as regular percentage changes, in order to better capture "psychological" price changes such as $-50 \%$. However, when time-series decompositions, econometric analysis or comparison with other studies are involved, we compute price changes as log-difference in prices.

\footnotetext{
${ }^{5}$ The methodology of data collection is described in Caillaud [1999], and also in Lequiller [1997].

${ }^{6}$ Some categories of goods and services are not available in our sample: centrally collected prices, among which car prices and administered prices (e.g. tobacco) or public utility prices (e.g. electricity), as well as other types of products such as fresh food or rents.

${ }^{7}$ When relevant, we divide prices by the indicator of quantity sold in order to recover a consistent price per unit.
} 
Outliers and imputed prices raise some concerns in the data set. We defined as outliers price change observations involving upward or downward changes by a factor larger than 5 , and trimmed them from the data. In case of missing prices, the INSEE imputes prices, typically by carrying forward the last non imputed price change. An important particular case is that of out-of-season items. We have removed those imputed observations from our baseline data set (details are available in Appendix Table A).

To produce aggregate measures of the frequency or size of price changes, we compute all statistics using CPI weights. Products categories (5-digit COICOP level) are the lowest level for which these CPI weights are available to us. There are close to 300 product categories in the data set. Although available CPI weights are not defined at the store/product level, the statistical office designs the list of outlets present in the sample to be representative in terms of market shares. Moreover, weights of CPI categories change every year. To control for possible changes in the composition of the CPI over time, we use average weights of CPI categories over the sample period. Our benchmark procedure for computing aggregate statistics from individual observations is as follows. The weight of an individual observation is set equal to the average weight of the CPI category over the period 2003-2011 (with weight set to zero at times when a product is not included in the CPI basket), divided by the number of observations in the category. This procedure gives the same importance in aggregation to all items belonging to the same category. For robustness purposes, we also have replicated our analysis, using the actual time-varying CPI weights, and results were not significantly altered.

\subsection{Sales and promotional discounts}

Our data set contains a variable that identifies whether a price corresponds to a sale price, either in the form of seasonal sales or temporary promotional discounts. ${ }^{8}$ These two kinds of sales are different in France and are regulated (contrary to the United States, United Kingdom or Germany). Seasonal sales are limited to specific time periods and the timing of seasonal sales periods is administered. Before 2009, seasonal sales were allowed twice a year for a six-week period each. With very small variations across years, the "winter sales" period covers from beginning of January to mid-February and the "summer sales" period covers from end of June to end of July. From 2009 a new law, Loi de Modernisation de l'Économie (LME), slightly modified the regulation on sales. The durations of fixed periods of sales was reduced from six to five weeks and a flexible period of sales (two weeks or two periods of one week), which can be freely set by stores, was introduced. During

\footnotetext{
${ }^{8}$ Field agents are instructed to flag a price as a seasonal sale or a temporary promotional discount if this is indicated next to the price when it is collected.
} 
seasonal sales, outlets are allowed to sell below cost. Contrary to seasonal sales, temporary promotional discounts are allowed at any time during the year but the seller cannot sell its product below cost and must deliver the discounted product during all the promotion period. To compute our price rigidity indicators, we consider two alternative assumptions. First, we include sales-related price changes, using all price records. Second, following Nakamura and Steinsson [2008], we exclude sales-related price changes: we consider that a price quote flagged by INSEE as "seasonal sales" or "promotional discounts" corresponds to a temporary price adjustment possibly irrelevant for macro analysis purpose, so that we replace the price by the last non-sale price. Thus, to compute price rigidity statistics without sales, we exclude any price decrease implied by sales, as well as the subsequent price increase that generally follows. In the remaining of the paper, we denote by "regular price" any non-sale price observation. A concern is that the INSEE flag identifying sales may be subject to measurement error, e.g. because the sales was not sufficiently visible within the outlet. To address this concern, as a robustness check we implement several "sales filters" that automatically identify temporary price changes, in the vein of inter alia Nakamura and Steinsson [2008]. The filters are described in the Appendix.

\subsection{Product substitutions}

Product substitution is an important concern in the analysis of micro price data. The statistical agency may stop recording the price of a given product in a given outlet, either because the product is no longer sold by the outlet or, more rarely, because the outlet itself closes (attrition/forced replacement), or because the statistical institute may decide to discard a product or an outlet in order to keep the sample of items representative of the structure of consumption (voluntary replacement). In our data set, when a given product in an outlet is definitively substituted by a similar one of another brand or of a different quality the substitution is tagged. When product substitution occurs, identifying price changes rely on assumptions. Three different possible assumptions on product replacements, differing in their consequence for price trajectories, can be distinguished. ${ }^{9}$ The first possibility is to consider that a new price trajectory starts with product substitution. Under this assumption, we simply discard from the sample the price change observation corresponding to product replacement. This simple approach has typically been followed in European empirical studies on price rigidity (for instance, Dhyne et al. [2006]). Alternative assumptions may however be relevant to characterize the implied price dynamics. In a second and third cases, the price trajectory is assumed to continue

\footnotetext{
${ }^{9}$ See Figure A in the Appendix for an illustration.
} 
at the time of product substitution, respectively not taking and taking into account the potential quality adjustment. A key feature of our data is that we do know which product substitutes the old one and, when relevant, the coefficient of quality adjustment. ${ }^{10}$ The implications of assuming that a price trajectory continues despite product replacement are particularly relevant in the analysis of some sectors where substitutions are frequent, such as clothing and durables goods. Following Klenow and Kryvtsov [2008] in our baseline analysis we consider that price trajectories continue after a product substitution, a case we refer to as "including product substitutions". Reasons for choosing this assumption as the baseline are twofold. First, forced substitution actually resembles pure and simple price changes. While we cannot distinguish between forced and voluntary substitutions, forced substitutions are likely much more common, as price collectors should diligently try to compare the same product and the consumption structure is slowly moving. Second, as will be documented below, including substitution-related price changes is necessary in order to match the aggregate inflation rate. For completeness purpose, we however report, as robustness checks, results assuming that price trajectories are stopped by a product substitution, as case we refer to as "excluding product substitutions". ${ }^{11}$

\subsection{Comparing France and the United States}

One aim of this paper is to compare the average frequency and size of price changes in France to those in the United States, controlling for possible differences in the coverage of products between French and US micro data sets and for differences in the weighting structure of both price indices. We here use the detailed results obtained by Nakamura and Steinsson [2008] on the frequency of price changes, increases and decreases (including or not sales and including or not substitutions) and on the average size of log-price increases and decreases calculated at the product level for the period 1998-2005. ${ }^{12}$ The product classification used to compute the CPI used in Europe, the COICOP (Classification of Individual Consumption According to Purpose), differs from the one used in the United States, the ELI (Entry Level Item). ${ }^{13}$ For France we have information for products at level 5 of the COICOP (resulting in 304 products), while for the United States Nakamura and Steinsson [2010b] report statistics for 278 ELI codes. Using the available

\footnotetext{
${ }^{10}$ Baudry et al. [2007] consider product replacements as price changes, but they do not observe the new product that substitutes the old one. In particular, in the instance of product substitution they cannot infer whether the implicit price change is an increase or a decrease.

${ }^{11}$ For further details on data treatment, see also Appendix.

${ }^{12}$ Tables 20 and 22 in Nakamura and Steinsson [2010b] supplementary material.

${ }^{13}$ See for instance Lane and Schmidt [2006] for a discussion of the difference between US and European CPI.
} 
information, we build a bridge table between COICOP and ELI product classifications to compare our aggregate results, mapping every given ELI product code to one or more 5-digit COICOP products. ${ }^{14}$ Besides, to control for differences in the weighting structures between the United States and France, we use this bridge table to apply the US weight structure to our French data. We are then able to compute French indicators of price rigidity using the US weight structure. One limitation to our comparison exercise is that individual prices for several categories of products are not available in our French data set whereas they are available for the United States. In particular, prices for fresh food, tobacco, drugs and medical services, some transport services and cars, postal and telephone services and electricity are not present in our micro data set, since most of them are centrally collected. Overall, we are able to match about $65 \%$ (in terms of CPI weights) of products available in the Nakamura and Steinsson [2008] data set to French products, which corresponds to about $45 \%$ of total US CPI weights and $60 \%$ of the CPI French weights. ${ }^{15}$

\section{Cross-Sectional Evidence on Price Adjustment}

Price rigidity is often approximated in macroeconomic models by the frequency of price changes. In this section, we present new results for France on the frequency and size of price changes, with a concern about the sensitivity of results to assumptions regarding sales and product substitutions. Moreover, we provide new facts on the distribution of price changes. We compare our findings to recent US results obtained on CPI price data.

\subsection{Frequency of price changes}

Table 1 provides the main statistics on the frequency of price changes and comparisons with findings from the United States, as reported by Nakamura and Steinsson [2008]. We first focus on our baseline case, which is "including substitutions and sales" (i.e. when both price changes related to product replacements and those related to sales are included). The average monthly frequency of price changes in France is $20.1 \%$ on the period 2003-2011, and the average implied price duration is about 9 months ${ }^{16}$ while the

\footnotetext{
${ }^{14}$ The bridge table is available upon request.

${ }^{15}$ One main source of the discrepancy between French and US coverage is shelter. Shelter is available neither in the US data set used by Nakamura and Steinsson [2008] nor in our French data set, but this has a lower impact on French CPI coverage, because the "owner-occupied" part of shelter is not included in scope of the French CPI.

${ }^{16}$ The mean implied duration is calculated averaging the inverse of price change frequency at product level.
} 
median is close to 6 months. Consumer prices appear much more flexible in the United States since Nakamura and Steinsson [2008] find that the frequency of price changes is $27.7 \%$ over the period 1998-2005. However, when restricting to the sample of products available in both data sets, and using the US weight structure, the difference is smaller: each month, $20.1 \%$ of prices change in France versus 24.1\% in the United States. Products whose prices are modified quite frequently like fresh food, cars or electricity are not available in the French data set, which explains at least partly this smaller difference in the frequencies of price changes. The proportion of price increases among all price changes is close to $60 \%$ in France, versus about $55 \%$ in the United States. ${ }^{17}$

\section{[ Insert Table 1 ]}

One important pattern of price rigidity is the large degree of sectoral heterogeneity. ${ }^{18}$ Table 2 shows the frequency of price changes for the four major sectors of products we consider. Prices in the energy sector are modified very often $(77.1 \%$ on average each month) whereas the frequency of price changes for manufactured goods or food are close to $20 \%$. The frequency of price changes is the lowest for services $(8.2 \%)$. The proportion of price increases is close to $60 \%$ in food, other manufacturing goods, and energy sectors, whereas it is lower for durables and clothing (around 50\%). In services, price decreases are rare: price increases amount to $77.6 \%$ of price changes. Similar findings were obtained for the United States (Nakamura and Steinsson [2008]).

\section{[ Insert Table 2]}

Many empirical studies emphasize that sales are common in the United States. A widespread conjecture is that the extent of sales is an important factor behind the differential in price flexibility between the United States and Europe. We now document some basic facts on the frequency of sales in France and their impact on the frequency of price changes. About $2.5 \%$ of price quotes are flagged by INSEE as sales or promotional discounts: the proportion of seasonal sales among price records is $0.7 \%$ and the proportion of temporary promotional discounts amounts to $1.7 \%$ (Table 1). Sales are much less frequent in France than in the United States: Klenow and Kryvtsov [2008] find that about $11 \%$ of price records are sales and Nakamura and Steinsson [2008] 7.4\%. Sales concentrate in some sectors (Table 2): about $10 \%$ of price quotes in the clothing

\footnotetext{
${ }^{17}$ The US figure here was computed in the "excluding substitutions" case, following information available in Nakamura and Steinsson [2008]

${ }^{18} \mathrm{~A}$ recent macroeconomic literature shows the relevance of sectoral heterogeneity in the frequency of price changes for the real effects of monetary policy (see for instance Carvalho [2006]).
} 
sector are promotional discounts or seasonal sales and $6 \%$ in durables whereas almost no price quotes are sales in energy or services. This sectoral heterogeneity is very similar to that found in the United States (even if the proportion of price quotes concerned by sales is much larger in the United States). If we disregard sales-related prices (i.e. when replacing any price flagged as sales or promotional discounts by the last previous "regular" price), the frequency of price changes is much lower than when sales are included: $17.4 \%$ of prices are modified each month and the proportion of price increases increases a little, from $60.2 \%$ to $62.3 \%$. We investigated the robustness of these numbers to the procedure used to detect sales by using "V-shape" sales filters (results are available Appendix Table B). Results are broadly similar. ${ }^{19}$

In the United States, Nakamura and Steinsson [2008] find that after excluding sales, the frequency of price changes decreases by almost 5 percentage points from $26.5 \%$ to $21.1 \%$, so that removing sales delivers closer figures for France and the United States. Moreover, when we restrict to products available in both data sets and use the US weight structure, the difference between the United States and France vanishes: the frequency of price changes is $17.4 \%$ in France and $17.1 \%$ in the United States. ${ }^{20}$

Nakamura and Steinsson [2012] recently illustrated the role played by product substitutions in price dynamics and their macroeconomic effects. ${ }^{21}$ We now investigate the effect of product substitution on the measurement of the frequency of price changes, recalling that in our baseline analysis we include price changes related to product substitutions. In France, about $4.1 \%$ of non-imputed price quotes correspond to a product substitution (Table 1). A similar figure is obtained on US CPI data: $3 \%$ and $3.4 \%$ of price quotes are product replacements according to respectively Klenow and Kryvtsov [2008] and Bils and Klenow [2004]). Disregarding price adjustments associated with product substitutions significantly alters the characteristics of price dynamics. The frequency of price change drops by about 2.5 percentage points, from $20.1 \%$ to $17.7 \%$. Whether or not we consider the INSEE correction for quality adjustment in the cases of substitution affects only marginally the frequency of price change. Our results are consistent with what is found on US data: considering price changes at product substitution increases the frequency of price changes by 1 to 2.5 percentage points: from $26.5 \%$ to $27.7 \%$ for

\footnotetext{
${ }^{19}$ The frequency of price changes on sales-filtered data is smaller by 1 to 2 percentage points; the additional temporary price changes detected by the filters tend to be small (as reported in Figure B in Appendix), pointing to measurement errors rather than genuine sales.

${ }^{20}$ As robustness checks, we run the same comparison excluding observations between 2008 and 2011 for France (when inflation varies more) and also excluding energy prices for both countries. The difference remains similar. See Table E in Appendix.

${ }^{21}$ Nakamura and Steinsson [2010a] suggest that the cost of price adjustment is low at product replacement; a firm may then wait for a predetermined product substitution to change its price.
} 
Nakamura and Steinsson [2008] and from 23.6\% to 26.1\% for Bils and Klenow [2004]. ${ }^{22}$ The incidence of product substitution is strongly heterogeneous across products and especially widespread in the manufacturing industry (Table 2). In particular, about $10 \%$ of clothing and durables price records are product replacements. Comparable findings are obtained by Nakamura and Steinsson [2008] on US data. On the other hand for food, services or energy, the substitution rates are much lower (close to or less than $2 \%$ in our data).

\subsection{The distribution of price changes}

The recent macroeconomic literature on price rigidity emphasizes some important results on the distribution of price changes: the average price changes are quite large, small price changes are frequent, as are large ones (Klenow and Malin [2010]). Those empirical results have spurred some theoretical models of price rigidity (see for instance Costain and Nakov [2011], Golosov and Lucas [2007], Klenow and Kryvtsov [2008] or Midrigan [2011]). We provide here new stylized facts on the distribution of price changes in France and compare them to US results.

Table 3 reports our basic findings on the size of price changes. The average size of price changes is rather large: $12.8 \%$ for price increases and $-11.5 \%$ for price decreases, while the median is much smaller $4.3 \%$ for price increases and $-6.1 \%$ for price decreases.

\section{[ Insert Table 3]}

Table 4 provides a comparison of France and the United States. To enhance comparability, we restrict to the common sample of products and provide summary statistics following the same approach as Nakamura and Steinsson [2008]: we compute the average size of log-price changes by product, then we compute (using product weights) the aggregate average price increase and decrease. We obtain that the average size of price changes in absolute value is lower in France than in the United States: a little more than $10 \%$ in France versus more than $15 \%$ in the United States. Overall, price changes are more frequent and larger in the United States compared to France. As stressed by earlier studies, the average size of price changes is large compared to the typical inflation rate, suggesting price changes do not simply correspond to inflation indexation, but incorporate idiosyncratic shocks with large variance.

\footnotetext{
${ }^{22}$ Baudry et al. [2004] find that when product replacements are included the frequency of price changes increases from 16.2 to $18.9 \%$; however, they consider that all product replacements are price changes (because the new product was not observable), whereas price changes are actually not systematic when products are replaced.
} 


\section{[ Insert Table 4]}

Table 5 reports results on the sectoral heterogeneity of the size of price changes. The sectoral heterogeneity of the average size of price changes is quite substantial. The average absolute size of price changes are larger than $20 \%$ for durables and clothing. On the contrary, average absolute price changes in the energy sectors are much smaller, less than $4 \%$ in absolute values. For food and other manufacturing goods, the size of price changes is on average about $10 \%$ and $13 \%$ in absolute value.

\section{[ Insert Table 5]}

Two important and related facts are discussed by the US empirical literature on price rigidity (including Eichenbaum et al. [2014], Klenow and Kryvtsov [2008] or Midrigan [2011]): the distribution of price changes has fat tails (i.e. large price changes are quite frequent) and the proportion of small price changes is large. We now provide related results on the distribution of price changes for France. ${ }^{23}$ Figure 1 plots the weighted (non-standardized) distribution of all non-zero price changes. The distribution has a mode between 1 and 3\%. The distribution has a "hole", with relatively few price changes between 0 and $1 \%$, and a smaller mode at price changes around $-1 \%$. Therefore, there is a slight asymmetry in the central part of the distribution. Finally, the distribution of price changes has noticeable peaks at large price increases and decreases reflecting "attractive" price changes related to sales, such as $-20,-30,-40,-50 \%$ and 25,33 and $50 \%$. These spikes to a large extent disappear when considering the distribution of non-sale price changes, also reported in the Figure 1.

\section{[ Insert Figure 1]}

Tables 3 and 5 also report statistics on the distribution of price changes. The proportion of small prices is quite large in France: $11.2 \%$ of price changes in absolute values are below $1 \%$ and around $23 \%$ of price changes are below 2\%. By comparison, Klenow and Kryvtsov [2008] on US price data find that 25\% of price changes are below $2.5 \%$ in absolute values and Vermeulen et al. [2012] find that a quarter of price increases and decreases in absolute values are smaller than $1.5 \%$ on producer prices. Eichenbaum et al. [2014] recently challenge this result for the United States. They argue that for a number of specific products such as cigarettes, gas services, electricity, telephone services or new cars measurement errors occur because prices are computed as unit value indices,

\footnotetext{
${ }^{23}$ Focusing on the kurtosis of price changes Alvarez et al. [2014] document in detail this pattern on the same data set and investigate their macroeconomic consequences.
} 
or include taxes, or pertain to a bundle of goods. They show that when these products are excluded the proportion of price changes lower than $1 \%$ is less than $5 \%$. However, most of those problematic products are not available in the data set we use (in particular, telephone services, electricity, gas, new cars or cigarettes). Furthermore, the items that remain in the data set are arguably all single-good transaction prices. We acknowledge however that some small price changes may be spurious, reflecting genuine measurement errors: evidence of this is given by the temporary small price changes detected by statistical filter (see Figure B in Appendix). However, even excluding these statistically detected transitory price changes does not alter our conclusion on the pervasiveness of small price changes. The abundance of small price changes is at odds with the predictions of simple models of price rigidity, in which small price changes are predicted to be rare. However, small price changes are more frequent in some specific sectors (in particular, in energy ${ }^{24}$, food and other manufacturing goods).

Large price changes are also common: the higher quartile of the distribution is $10.9 \%$ for price increases and $16.1 \%$ in absolute value for price decreases (Table 3). Golosov and Lucas [2007] and Midrigan [2011] show that the extent of large price changes cannot be explained within a simple menu cost model, and suggest that this likely reflects the existence of large idiosyncratic shocks. Large price changes are more frequent in durables and the clothing sector whereas in energy, services, and other manufacturing goods the distribution of price changes is less dispersed (Table 5).

The size of price changes is typically larger, in absolute value, during sales. The average size of price decreases during sales is about $-25 \%$ (versus $-10 \%$ overall) (results on size of sales price change are available in Appendix Table J). This is in line with Nakamura and Steinsson [2008] who find a median size of price change of $29.5 \%$ in absolute value. Price decreases during "seasonal sales" are deeper than those during "promotional discounts" (about $-35 \%$ versus $-20 \%$ on average). Sales have a prominent contribution to the average size of price changes (Table 3). When we consider only non-sales prices, the average size of price changes in absolute value is about $8 \%$, versus about $12 \%$ when including sales. ${ }^{25}$ To compare French and US results, we compute over the common sample of products the average size of log-price changes in both countries excluding sales (Table 4). The average size of price increases is $6.0 \%$ in France versus $9.2 \%$ in the United States, whereas for price decreases the average price change is $-9.0 \%$ in France and $-12.0 \%$ in the United States. As in the case of frequencies, sales contribute a lot to the difference in the average size of price changes between France and the United States. The

\footnotetext{
${ }^{24}$ See for example Gautier and Le Saout [2014] for gasoline prices at higher frequency.

${ }^{25}$ Results are robust to using V-shaped sales filters, see Appendix Table C.
} 
dispersion of the price change distribution excluding sales is smaller than when sales are included since the number of large price increases and decreases drops substantially when excluding sales (the 75 th percentile of price decreases is $-10.0 \%$ versus $-16.1 \%$ including sales). The exclusion of sales substantially reduces the sectoral heterogeneity in the size of price changes (Table 5).

We now briefly discuss the influence of including price changes related to product substitutions on the assessment of price change size. The average price increases and decreases are lower in absolute value when substitution-related price changes are not considered. In particular, the average size of price increases is lower by around 4 percentage points (8.9\% versus $12.8 \%$ ) when replacements are excluded (Appendix Table I provides detailed results). For retailers, product replacement seem to appear as an opportunity to increase prices. As a result, including substitution is crucial for matching the aggregate inflation rate. These findings on substitutions are qualitatively similar to those available for the United States.

\section{Time-Series Evidence on Price Adjustment}

Inflation results from the aggregation of individual price adjustment behaviors: inflation may increase because more firms change their prices (the extensive margin) or because firms change their prices by a larger amount (the intensive margin). We here investigate how these two dimensions of individual behavior of price adjustment contribute to inflation dynamics over time. Meanwhile, we document the impact of sales and substitutions on inflation. We also analyze how individual price changes themselves respond to aggregate inflation and business cycle conditions. In particular, we investigate the stability of price adjustment behavior during the 2008-2009 Great Recession.

\subsection{Decomposing inflation variations}

Following Klenow and Kryvtsov [2008], we decompose the inflation rate into an extensive margin (the frequency of price changes) and an intensive margin (the mean size of price changes). The inflation rate can be written as the product of the frequency of price changes by the average size of price changes:

$$
\pi_{t}=F_{t} \cdot d p_{t}
$$

where $\pi_{t}$ is the approximation of the weighted monthly inflation rate using our micro data, $F_{t}$ is the weighted monthly frequency of price changes, and $d p_{t}$ is the weighted 
average size of all non-zero price changes (defined as the first-differences of log-prices between month $t$ and $t-1$ ).

This approximation can be further decomposed by considering separately price increases and price decreases:

$$
\pi_{t}=F_{t}^{+} \cdot d p_{t}^{+}+F_{t}^{-} \cdot d p_{t}^{-}
$$

where $F_{t}^{+}$and $F_{t}^{-}$are respectively the frequency of price increases and the frequency of price decreases, and $d p_{t}^{+}$and $d p_{t}^{-}$are the average size of price increases and the average size of price decreases.

First, Table 6 reports some summary statistics on the approximated inflation rates computed at the product level (including or not sales and substitutions) and it compares those statistics with moments of the actual inflation rates. ${ }^{26}$ When sales and product replacements are included, the median correlation between our recomposed monthly inflation rates and the monthly inflation rates published by INSEE (excluding energy) is fairly large (0.826). The median correlation is lower when sales are excluded (0.70), reflecting that sales are included in INSEE price indices. When sales are included, the median of average monthly recomposed inflation rates is close to the median of average inflation rates ( 0.185 versus 0.170 in INSEE data), and the median standard deviation of inflation matches the one found in INSEE data (0.454 versus 0.460). When we remove sales-related price changes from the data, the average recomposed inflation rate is unchanged. Indeed sales-related price changes include price increases after the sales episodes, which tend to offset the decrease at the time of the sales (Table $\mathrm{J}$ in Appendix provides detailed results). At the same time, the volatility of the inflation rate is much lower when excluding sales: 0.366 versus 0.454 (Table 6). When discarding substitutions, the average and the volatility of the approximate inflation rate are lower than the average and volatility of the actual inflation rate.

\section{[ Insert Table 6 ]}

We then investigate the relative contribution of the frequencies and the sizes of price changes to the French aggregate monthly inflation rate. ${ }^{27}$ For that, we consider deviations

\footnotetext{
${ }^{26}$ Price indices at a disaggregated level are only available from INSEE at level 4 of the COICOP classification (134 products).

${ }^{27}$ We here compute the approximation from aggregate time series of frequencies and sizes of price increases and decreases. This implies matching the volatility of aggregate inflation less accurately, but the correlation with headline aggregate inflation is still very high (about 0.8).
} 
of inflation $\tilde{\pi}_{t}$ from its average over time $\bar{\pi}$ and we write the inflation rate as:

$$
\pi_{t}=\tilde{\pi}_{t}+\bar{\pi}
$$

We then consider deviations of frequencies and sizes of price changes from their averages over time:

$$
\widetilde{\pi}_{t}+\bar{\pi}=\left(\bar{F}^{+}+\widetilde{F}_{t}^{+}\right) \cdot\left(\overline{d p}^{+}+\widetilde{d p}_{t}^{+}\right)+\left(\bar{F}^{-}+\widetilde{F}_{t}^{-}\right) \cdot\left(\overline{d p}^{-}+\widetilde{d p}_{t}^{-}\right)
$$

Rearranging terms, it is possible to single out the contributions of the frequency and the size of price changes to the variations of the monthly inflation rate:

$$
\tilde{\pi}_{t}=\underbrace{\left(\widetilde{F}_{t}^{+} \cdot \overline{d p}^{+}+\widetilde{F}_{t}^{-} \cdot \overline{d p}^{-}\right)}_{\text {frequency contribution }}+\underbrace{\left(\bar{F}^{+} \cdot \widetilde{d p}_{t}^{+}+\bar{F}^{-} \cdot \widetilde{d p}_{t}^{-}\right)}_{\text {size contribution }}+\underbrace{\left(\widetilde{F}_{t}^{+} \cdot \widetilde{d p}_{t}^{+}+\widetilde{F}_{t}^{-} \cdot \widetilde{d p}_{t}^{-}\right)}_{\text {residual }}
$$

We compute the terms of this decomposition using our data set of individual price quotes excluding energy and including substitution-related price changes. We consider both the cases including and excluding sales.

\section{[ Insert Table 7 ]}

Table 7 reports the correlations between monthly inflation and the frequency and size of price changes. The monthly inflation rate is positively correlated with the average size of price increases and decreases: correlation coefficients are above 0.50 in each case. Correlation with frequency is noticeably lower. Figure 2 shows the contributions of frequencies of price increases and decreases (black solid line) and those of the size of price increases and decreases (black dashed line) to monthly inflation deviations from its average (gray solid line). Inflation variations are mostly explained by the size contribution, while the contribution of the extensive margin is lower. The large contribution of the intensive margin to inflation variations at the monthly frequency seems mostly driven by large movements in the size of price changes due to seasonal sales.

\section{[ Insert Figure 2 ]}

Inflation excluding sales is highly correlated with the frequency of price changes (0.56). This correlation stems from a large positive correlation with the frequency of price increases (0.76) and to a lower extent from the negative correlation with the frequency of price decreases $(-0.20)$. Nakamura and Steinsson [2008] obtain similar results on US data. The larger correlation with the frequency of price increases can be explained by 
a positive inflation trend, which makes the distribution of relative prices asymmetric. When excluding sales, the correlation between inflation and size of price increases is negative. Figure 3 plots the contributions of the frequency and size of price changes when sales are excluded. Contrasting with Figure 2, the contribution of the frequency of price increases and decreases (black solid line) to inflation fluctuations is much larger than the contribution of sizes (black dashed line). Moreover, Figure 3 also shows the January effect exists even when sales are excluded: in January, the peak in the frequency of price increases has a clear positive effect on the monthly inflation rate (gray solid line).

\section{[ Insert Figure 3 ]}

Finally, we find that, unlike sales, substitutions play a limited role to account for fluctuations in inflation over time (Figure $\mathrm{C}$ in Appendix), although incorporating substitutionrelated price changes is crucial to match the average aggregate inflation rate. That last feature reflects the typical life cycle for some products: after being discontinued, a product is typically replaced by a new one with a price often larger than the previous "regular price" of the replaced item.

\subsection{The seasonality of price changes}

The decomposition of inflation variations shows the relevance of seasonal movements in the monthly inflation rate. Olivei and Tenreyro [2007, 2010] obtain that the seasonality of wage setting patterns may have an impact on the effects of the monetary policy. We now further document the seasonality of the frequency and size price changes and assess the contribution of sales and substitutions to this seasonality.

\section{[ Insert Figure 4]}

Figure 4 plots the average frequency of price changes (black solid line), increases (gray solid line) and decreases (gray dashed line) across months of the year. As in the United States, the frequency of price changes decreases slowly across the months within the year. The frequency of price changes shows a significant peak in January $(27 \%)$, two smaller peaks in July and September (about 21\%) and a through in December $(16.2 \%)$. The seasonal pattern of the frequency of price changes mainly stems from the seasonality of price increases: the frequency of price increases is $16.8 \%$ in January and gradually decreases throughout the year to below $10 \%$ during the fourth quarter. The frequency of price decreases also exhibits two peaks at around 10\% in January and July, reflecting seasonal sales especially in the clothing and durable sectors. Figure 5 presents 
the frequency of price changes, increases, and decreases by month of the year for six sectors. The frequency of price changes exhibits a peak in January in all sectors (except energy and food). The peak is very marked in services: the frequency of price changes is above $15 \%$ in January versus less than $7 \%$ the rest of the year. In services there is also a peak in the frequency of price increases in September. In the manufacturing sector (in particular clothing) the frequency of price decreases has noticeable peaks in January and July, while that of price increases has peaks in February and August.

\section{[ Insert Figure 5 ]}

Sales contribute significantly to the seasonal movements in the frequency of price changes. As discussed in section 2, seasonal sales are regulated in France and by law take place mostly in January-February and June-July, while temporary discounts are less seasonal (Table $\mathrm{K}$ in Appendix). The seasonality of sales is quite similar in the United States, although their frequency does not decrease as much after January and July there (Nakamura and Steinsson [2008]). Figure 6 plots the frequencies of price changes, increases, and decreases by month including or not sales. When excluding sales (solid lines), the frequency of price decreases becomes essentially flat, whereas the frequency of price increases still has a peak in January and is decreasing across the months of the year (Figure D in the Appendix documents sectoral heterogeneity). Overall, the noticeable peak in January in the frequency of price changes and the smaller one in September are mostly due to seasonal price increases, mainly due to services.

\section{[ Insert Figure 6 ]}

Product substitutions are less seasonal than sales. They are somewhat more frequent in March and September-October, that is, after seasonal sales. ${ }^{28}$ The seasonal patterns of the frequency of price changes are not modified by considering product substitutions or not. Nakamura and Steinsson [2010a] report a similar pattern for the United States.

\section{[ Insert Figure 7 ]}

Similarly to the frequency, the size of price changes has strong seasonal patterns. Figure 7 shows the average size of price increases and decreases by month of the year, including or not sales. Price decreases are larger in January and July: the average price decrease is around $-16 \%$ versus $-11.3 \%$ on average over the year (black dashed line).

\footnotetext{
${ }^{28}$ For clothing, about one third of observations are replacements in March and in September (see Appendix Table L).
} 
Price increases are larger in the February-March and August-September (black solid line): the average price increases is then above $15 \%$ versus $12.8 \%$ on average. These patterns are obviously related to large price variations during sales. ${ }^{29}$ When we consider only non-sales prices, the seasonality of the size of price changes almost disappears (gray lines).

Explaining the seasonality of price changes is beyond the scope of this paper. We may note that motives for seasonal patterns, beyond administrative rules on sales, include endogenous synchronization of price changes as well as the pattern of wages. Seasonality of wage changes in France is documented in particular in Avouyi-Dovi et al. [2013] and Le Bihan et al. [2012]. Another motive for seasonality is provided by Alvarez et al. [2011] based on a rational inattention-type argument: when there is a large "information cost" to observe or compute the optimal price, it is an optimal policy to reset prices at discrete pre-set intervals.

\subsection{The effect of aggregate fluctuations on sales and substitu- tions}

Sales and to a lesser extent substitutions are seasonal and contribute to the seasonality of the frequency and the size of price changes. Beyond seasonal variations, an important issue we want to examine is to what extent price changes associated with sales and product substitutions respond to inflation and business cycle conditions. One motivation is that a recent literature suggests that price changes associated with sales have different determinants than regular price changes, which justifies discarding sales-related price changes when computing indicators of price rigidity. To assess whether sales respond to macroeconomic variables, we estimate at the micro level, a Probit model on sales occurrence and OLS regression on the size of the price drops that initiate a sales price spell. The exogenous variables are the cumulative inflation rate at the 4-digit product level since the last price change in a given outlet ${ }^{30}$, the aggregate unemployment rate and a dummy variable for the Great Recession. ${ }^{31}$ Year, month and product dummies are also included.

Table 8 reports marginal effects obtained from the Probit model and parameter estimates of the OLS regressions. We find that the sensitivity of both the probability and

\footnotetext{
${ }^{29}$ Appendix Table $\mathrm{J}$ documents the size of sales-related price changes.

${ }^{30}$ Product inflation rate is calculated from our micro data set excluding sales observations since due to regulation, sales are extremely synchronized across items, so the aggregate inflation rate (which is highly correlated to the dynamics of sales) will be mechanically correlated to the incidence and size of sales at the individual level.

${ }^{31}$ As there is no benchmark business cycle dating for France and the euro area cycle is well correlated with that of the French economy, we use a dummy for recession dates as identified by the CEPR.
} 
size of sales price changes to cumulative inflation and unemployment is quite low. The size of sales-related price decreases is even not significantly affected by macroeconomic variables. Cumulative inflation at a disaggregated product level has a small negative effect on the probability of sales whereas unemployment has a small positive impact. The impact of the "Great Recession" dummy on the probability of observing a sales price is positive, but mild (0.22 percentage point). ${ }^{32}$ However, the effect of the crisis may be empirically difficult to disentangle from the impact of the change in competition regulation (LME), which occurred in January 2009 and softened restrictions on sales. Moreover, the fact that seasonal sales are regulated in terms of their timing may blur the assessment about the effect of macroeconomic covariates. Restricting to "temporary promotional discounts" (i.e. excluding seasonal sales) delivers smaller and less significant effects of macroeconomic variables on temporary discounts, as reported in the last two columns of Table 8. Contrary to results obtained by Klenow and Willis [2007], sales do not seem to reflect recent developments on aggregate prices, but to depend more on idiosyncratic shocks or regulation. Anderson et al. [2012] and Coibion et al. [2012] provide similar evidence for the United States.

We also examine whether inflation or business cycle conditions affect product substitutions and the size of price changes related to product substitutions. Table 9 reports marginal effects obtained from a Probit model and parameter estimates of the OLS regressions on product substitution-related price changes. The exogenous variables are the same as above (cumulative inflation at a disaggregated product level, unemployment and a dummy variable for the Great Recession). Like for sales-related price changes, we observe that the effects of macroeconomic variables on both size and probability of price changes related to product replacements are small. This suggests that product substitutions are not driven by inflation developments, but more likely by other long-term firm decisions like product development cycle or seasonality of demand. This last result is consistent with those obtained by Klenow and Willis [2007] on US data using similar regressions.

\subsection{The effect of aggregate fluctuations on regular prices changes}

We now examine to which extent macroeconomic information affect the probability and the size of regular price changes, which can enlighten the dynamics of aggregate inflation. The recent period was characterized by relatively large shocks, such as the increase in the level and volatility of oil price and the Great Recession. Figure 8 displays the evolution

\footnotetext{
${ }^{32}$ As illustrated in Figure E in the Appendix, the frequency of sales remains stable all over the sample period.
} 
of headline inflation and inflation excluding energy over the period 2003-2011. Inflation was relatively stable, except for between 2007 and 2008 when it increases to a value of more than 3.5\% and then quickly decreases in 2009 hitting negative values. While the fall of inflation corresponds to the recession (GDP growth was $-1.5 \%$ in the first quarter of 2009), the episode of inflation volatility also reflects the volatility of energy prices and inflation excluding energy appears much more stable. A simple Phillips curve would suggest that inflation may vary for three reasons: a change in inflation expectations, a variation in marginal costs, or a modification in the degree of price rigidity. Movements in the frequency of price changes over time can be related to a modification in the degree of price rigidity. Variations of the size of price changes may mirror fluctuations in the marginal costs. To understand variations in the inflation rate, we here analyze the determinants of the probability and the size of price changes at the micro level.

\section{[ Insert Figure 8 ]}

Figure 9 shows the evolution of the frequencies of price changes, increases and decreases excluding sales. We plot the frequency of price changes from August 1994 to April 2011, using the frequency of price changes computed by Baudry et al. [2007] to extend the sample. Using a moving average to filter out the seasonal patterns, the frequency of price changes is broadly stable over the period 1994-2011, at levels between $15 \%$ and $20 \%$ (black solid line). Its main fluctuations reflect movements in commodity prices (in particular in the periods 1999-2000 and 2008-2009), VAT changes in 1994 and in 2000, and the euro cash changeover in January 2002. The frequency of price changes seems to have slightly increased at the time of the Great Recession: the frequency of price changes is a little less than $17 \%$ between 2003 and 2008 and about $18 \%$ after 2008 and the beginning of the recession.

\section{[ Insert Figure 9 ]}

Figure 10 shows the average (solid lines) and the median (dashed lines) sizes of price changes over time for the period 1994-2011 excluding sales. The average and median sizes of price decreases and increases are rather stable until 2008. Over the period 2008 to 2011 measures of the output gap are typically negative, and both the average and the standard deviation of price increases are larger than previously. For instance, before 2008, the standard deviation of price increases was less than 6.5, while it is 8.6 between 2008 and 2011. Turning to price decreases, results are similar: the absolute size and standard 
deviation are larger after 2008. ${ }^{33}$ Berger and Vavra [2012] provide similar evidence for the United States, and argue that the increase in the volatility of price changes reflects an increase in the variance of shocks and macroeconomic uncertainty.

\section{[ Insert Figure 10 ]}

To investigate the effect of inflation and business cycle conditions on regular price changes at the micro level, we estimate Tobit type II models for price increases and price decreases. In this model, a first equation examines the determinants of the probability of regular price changes, while a second equation explains the size of price changes (the model in presented in more details in the Appendix). Our specification thus accommodates discreteness in price change and allows to separate the extensive and intensive margins. In the first equation, we explain the probability of price increases (or decreases, in the case of the model for price decreases) by relating it to the cumulative inflation rate at the 4-digit product level since the last price change of the outlet ${ }^{34}$ and to a vector of variables capturing business conditions (the aggregate unemployment rate and a dummy for the Great Recession, as identified by the CEPR). Year, month and product dummies are also included. When a price increases (or decreases), the second equation accounts for the size of the price change controlling for the selection effect (i.e. the fact that the determinants of the first stage regression did actually trigger a price change). This equation relates the size of price changes to the same determinants as in the first equation. Yet, for identification reasons, the monthly dummies included in the price change decision equation are excluded from the size equation: we here assume that the month of the year is relevant for outlets in the timing of their price decisions (because of annual contracts, holidays...), but that it has no specific effect on the size of price changes. Our exercise is similar in spirit to the regressions using aggregate frequency and size performed e.g. by Nakamura and Steinsson [2008]. We expect however that using micro data and cumulative inflation enhances identification.

We exclude price records from the energy sector from our estimation data set. Indeed, since the degree of price flexibility is much higher in this sector, it seems unlikely that the same model can fit energy and non-energy price records. Moreover, this is a crude

\footnotetext{
${ }^{33}$ Most of the changes in average size and standard deviations are statistically significant according to a formal test allowing for heteroscedasticity and autocorrelation correction and controlling for macroeconomic variables. Detailed results are presented in Appendix Table F and G.

${ }^{34}$ Product-level inflation is calculated using our micro prices excluding sales to obtain a proxy for sectoral cost shocks. Our maintained assumption is that product-level inflation is exogenous for the price setter at the outlet level. We also underline that cumulative inflation varies between outlets and over time, which is an important source of identification in our exercise.
} 
way to avoid confounding effects of the business cycle with those of commodity prices, as the recession is contemporaneous to large fluctuations in commodity prices.

\section{[ Insert Table 10]}

Table 10 reports marginal effects of the Tobit models obtained separately for price decreases and price increases (excluding sales). First, cumulative product-level inflation has a significant positive effect on the probability of price increases and a significant negative effect on the probability of price decreases, as expected. The marginal effect we undercover with Tobit models is moderate: an additional 1 percentage point of inflation raises the probability of a price increase by 0.290 percentage point, and reduces that of a price decrease by 0.194 . As regards the size of price changes, the signs of the parameters are also in line with intuition and significant, although the effect are quantitatively small. Using related regressions, Nakamura and Steinsson [2008] find similar evidence for probability of price changes, but do not obtain significant effects for the size of price changes.

Turning to the effect of the aggregate unemployment rate, it is found to be negative on the probability of price increase and positive on the probability of price decrease, consistently with intuition. ${ }^{35}$ The effect of unemployment on the size of price increase is negative as expected, while its effect on the size of price decrease is non-significant. Similarly to the effect of product-level inflation, the sensitivity to business cycle conditions seem to work through variations in the probability of price increase and decrease, more than through variation in sizes.

The impact of the "Great Recession" on probability of price decrease is positive and its effect on size of price decrease is negative (price decreases are larger in absolute value), in line with intuition. The effect of the recession dummy on the probability and the size of price increase is positive, a less straightforward outcome, but consistent with results suggesting that the Great Recession induced more volatility in prices (Vavra [2014] for the United States and Dixon et al. [2014] for the United Kingdom). We however find that the quantitative impact is limited: the impact of the recession on the frequency of price increase is estimated to less than 0.5 percentage point and 0.27 on the frequency of decreases. One concern is that the effect of Great Recession might be confounded with that of the large fluctuations in commodity prices observed during the crisis. We run an estimation incorporating cumulative oil price change to control for commodity price fluctuations. Results (presented in Appendix Table M) indeed point to an identification

\footnotetext{
${ }^{35}$ For robustness check, we also ran the same regressions with output gap as an alternative business cycle indicator and found similar results.
} 
issue, as the effect of the Great Recession becomes either non-significant or smaller when controlling for oil fluctuations (while the effect of unemployment is rather robust). However, the effect of oil price is small and has an unexpected negative sign. ${ }^{36}$ A further test is to restrict our sample to services prices, which are arguably less affected by oil prices. For this sector, the Great Recession dummy is significant and whether or not including oil price variations has only minor effects on estimated parameters (Table $\mathrm{N}$ in Appendix). Overall, the effect of the Great Recession on both the frequency and size of price change, is generally found positive, but is quantitatively small and should be regarded with some caution due to some identification difficulties.

Overall, fluctuations in the probability of price increase and decrease at the micro level, which play a substantial role in inflation dynamics, appear to respond to business cycle conditions and sectoral cost proxies. These results are qualitatively consistent with state-dependent models of price setting. At the same time, monthly dummies included in our model are still statistically significant, and point to some time-dependent patterns in price setting. Moreover another caveat is that in a Calvo model, the overall frequency of price changes is constant, but the share of increase and decrease can respond to the business cycle.

\section{Conclusion}

To conclude, we summarize our main stylized facts and discuss some of their possible macroeconomic implications.

First, one fifth of prices change each month in France. For the available common sample of products and using US weighting structure, the frequency of price changes is higher in the United States than in France (24.1\% versus 20.1\%). When sales are excluded however, the difference is very limited (around $17 \%$ both in the United States and in France). Our baseline estimates incorporate price changes related to product substitutions. This has rather similar consequences in France and in the United States: the estimated frequency of price changes in both countries is larger by about 2 percentage points than when disregarding substitution-related price changes. Similarly, the average size of price changes is larger in the United States, but when sales are excluded the difference appears much smaller. This raises two concerns for macro models. First, it emphasizes the need for a better understanding of the determinants of sales and their macro implications (e.g. Kehoe and Midrigan [2010] suggest that the actual degree of

\footnotetext{
${ }^{36}$ The cumulative product-level inflation since the last price change may already account at least partly for changes in commodity or inputs prices and the negative sign can reflect multicollinearity.
} 
price stickiness is mainly driven by the frequency of regular price changes). Second, it raises the importance to assess whether structural differences in costs of adjustments, or differences in the volatility of micro or aggregate shocks can help to understand similarities and differences between France and the United States in price adjustment characteristics.

A second set of noticeable facts relates to the distribution of price changes. The shares both of small and of large price changes is substantial. This fact is robust to taking into account sales and product substitutions, although the sizes of price increases and decreases are strongly reduced when we exclude sales. The average price change is about $12 \%$ in absolute values when product replacements and sales are included, and about $8 \%$ when sales are excluded. The inclusion of product substitutions increases a little the size of price changes. The distribution of price changes is quite dispersed and leptokurtic, consistent with what has been obtained by Midrigan [2011] for instance. The large size of price changes suggests a large variance in idiosyncratic shocks, whereas the extent of small price changes suggest more complicated forms of adjustment costs than a basic menu cost model (as suggested by Costain and Nakov [2011] or Midrigan [2011]). A recent theoretical literature emphasizes that designing macroeconomic models able to reproduce those facts alters the monetary policy responses to shocks (see for instance Alvarez et al. [2014]).

Third, we also find a strong seasonality of price changes even after controlling for sales. About $27 \%$ of prices are modified in January (versus about $20 \%$ on average). We find that this "January effect" on the frequency of price changes still exists even when sales are excluded, and contributes to a large extent to variations of the monthly inflation rate. This is in line with predictions of a non-staggered Taylor contract model, or could be explained by a strong degree of synchronization of price changes. When sales are excluded, the average sizes of price increases and decreases are broadly flat over the months of the year. Olivei and Tenreyro [2007, 2010] show that seasonality in wage-setting may have important consequences for the real effects of monetary policy, which may then depend on the quarter where a shock occurs. One can expect similar macroeconomic consequences for prices since regular prices appear - at least - as seasonal as wages.

Fourth, sales contribute significantly to the volatility of the inflation rate but we also find that price changes associated with sales and product replacements are much less sensitive to inflation variations or business cycle conditions than regular price changes. Sales presumably respond to idiosyncratic shocks and other long-term firm decisions. In particular, the Great Recession had almost no impact on price changes related to sales or substitutions. This result may be consistent with predictions of rational inattention 
models where firms' price decisions are more driven by idiosyncratic shocks than by macro ones (Mackowiak and Wiederholt [2009]).

Fifth, we find that inflation dynamics are mainly driven by fluctuations over time in the frequency of price increases and decreases. We also obtain that the probability (and to a lesser extent the size) of regular price changes responds to business cycle conditions and sectoral cost proxies. These results are qualitatively consistent with state-dependent models of price setting. However, we find only small changes in price adjustment patterns during the Great Recession. The frequency and the absolute size of price decreases only slightly increased. Moreover, the dispersion of the price change distribution also increased, which is quite consistent with some recent US findings. The stability of the frequency of price changes during the Great Recession raises the question of whether it merely reflects price stickiness, or whether it can be explained by some increased rigidity in marginal costs in the recent period. 


\section{References}

Alvarez, F., H. Le Bihan, and F. Lippi (2014). Sticky prices, menu costs and the effect of monetary shocks: theory and micro-evidence. NBER Working Paper 20155.

Alvarez, F. E., F. Lippi, and L. Paciello (2011). Optimal Price Setting With Observation and Menu Costs. The Quarterly Journal of Economics 126(4), 1909-1960.

Anderson, E., E. Nakamura, D. Simester, and J. Steinsson (2012). Temporary sales: On autopilot and "funded" by frequent flyer accounts. Working Paper.

Avouyi-Dovi, S., D. Fougère, and E. Gautier (2013). Wage Rigidity, Collective Bargaining, and the Minimum Wage: Evidence from French Agreement Data. The Review of Economics and Statistics 95(4), 1337-1351.

Baudry, L., H. Le Bihan, P. Sevestre, and S. Tarrieu (2004). Price rigidity evidence from the french CPI micro-data. ECB Working Paper 384.

Baudry, L., H. Le Bihan, P. Sevestre, and S. Tarrieu (2007). What do thirteen million price records have to say about consumer price rigidity? Oxford Bulletin of Economics and Statistics 69(2), 139-83.

Berger, D. and J. Vavra (2012). Dynamics of the U.S. price distribution. Working Paper.

Bils, M. and P. J. Klenow (2004). Some evidence on the importance of sticky prices. Journal of Political Economy 112(51), 947-85.

Caillaud, A. (1999). Pour comprendre l'indice des prix. INSEE Méthodes 81-82.

Carvalho, C. (2006). Heterogeneity in price stickiness and the real effects of monetary shocks. Frontiers of Macroeconomics 2(1), 1-56.

Coibion, O., Y. Gorodnichenko, and G. Hong (2012). The cyclicality of sales, regular, and effective prices: Business cycle and policy implications. Working Paper NBER No. 18273.

Costain, J. and A. Nakov (2011). Price adjustments in a general model of state-dependent pricing. Journal of Money, Credit and Banking 43(2-3), 385-406.

Dhyne, E., L. J. Alvarez, H. Le Bihan, G. Veronese, D. Dias, J. Hoffmann, N. Jonker, P. Lunnemann, F. Rumler, and J. Vilmunen (2006). Price changes in the Euro Area and the United States: Some facts from individual consumer price data. The Journal of Economic Perspectives 20(2), 171-192. 
Dixon, H., K. Liuntel, and K. Tian (2014). The impact of the 2008 crisis on UK prices: what we can learn from the CPI microdata. Cardiff Economics Working Papers,E2014/7.

ECB (2012). The development of prices and costs during the 2008-2009 recession. Monthly Bulletin ECB, April 2012.

Eichenbaum, M., N. Jaimovich, S. Rebelo, and J. Smith (2014). How frequent are small price changes? American Economic Journal: Macroeconomics 6(2), 137-55.

Gagnon, E. (2009). Price setting during low and high inflation: Evidence from Mexico. Quarterly Journal of Economics 124(3), 1221-1263.

Gautier, E. and R. Le Saout (2014). The dynamics of gasoline prices: Evidence from daily French micro data. Journal of Money, Credit and Banking, Forthcoming.

Golosov, M. and R. E. Lucas (2007). Menu costs and Phillips curves. Journal of Political Economy 115, 171-199.

Guimaraes, B. and K. Sheedy (2011). Sales and monetary policy. American Economic Review $101(2), 844-876$.

Kehoe, P. and V. Midrigan (2010). Prices are sticky after all. Working Paper NBER No. 16364.

Klenow, J. P. and B. Malin (2010). Microeconomic evidence on price-setting. Handbook of Monetary Economics 3, 231-284.

Klenow, J. P. and J. Willis (2007). Sticky information and sticky prices. Journal of Monetary Economics 54, 79-99.

Klenow, P. J. and O. Kryvtsov (2008). State-dependent or time-dependent pricing: Does it matter for recent US inflation? The Quarterly Journal of Economics 123(3), 863904.

Lane, W. and M. L. Schmidt (2006). Comparing US and European inflation: the CPI and the HICP. Monthly Labor Review.

Le Bihan, H., J. Montornès, and T. Heckel (2012). Sticky Wages: Evidence from Quarterly Microeconomic Data. American Economic Journal: Macroeconomics 4(3), 1-32.

Lequiller, F. (1997). L'indice des prix à la consommation surestime-t-il l'inflation? Économie et Statistique. 
Mackowiak, B. and M. Wiederholt (2009). Optimal sticky prices under rational inattention. American Economic Review 99(3), 769-803.

Midrigan, V. (2011). Menu costs, multi-product firms, and aggregate fluctuations. Econometrica 79(4), 1139-1180.

Nakamura, E. and J. Steinsson (2008). Five facts about prices: A reevalutaion of menu cost model. Quarterly Journal of Economics 123(4), 1415-1464.

Nakamura, E. and J. Steinsson (2010a). Monetary non-neutrality in a multisector menu cost model. Quarterly Journal of Economics 125(3), 961-1013.

Nakamura, E. and J. Steinsson (2010b). More facts about prices supplement to: five facts about prices: A reevaluation of menu cost models. mimeo.

Nakamura, E. and J. Steinsson (2012). Lost in transit: Product replacement bias and pricing to market. American Economic Review 102(7), 3277-3316.

Nakamura, E. and J. Steinsson (2013). Price rigidity: Microeconomic evidence and macroeconomic implications. Annual Review of Economics forthcoming.

Olivei, G. and S. Tenreyro (2007). The timing of monetary policy shocks. American Economic Review 97(3), 636-663.

Olivei, G. and S. Tenreyro (2010). Wage-setting patterns and monetary policy: International evidence. Journal of Monetray Economics 57(7), 785-802.

Smets, F. and B. Mackowiak (2009). On implications of microeconomic price data for macroeconomic models. Understanding Inflation and the Implications for Monetary Policy: A Phillips Curve Retrospective.

Turvey, R. (1999). CPI terminology. Working Paper, Joint ECE/ILO Meeting of Consumer Price Indices.

Vavra, J. (2014). Inflation Dynamics and Time-Varying Volatility: New Evidence and an Ss Interpretation. The Quarterly Journal of Economics 129(1), 215-258.

Vermeulen, P., D. Dias, M. Dossche, E. Gautier, I. Hernando, R. Sabbatini, and H. Stahl (2012). Price setting in the Euro area: Some stylised facts from individual producer price data. Journal of Money, Credit and Banking 44 (8), 1631-1650.

Wulfsberg, F. (2010). Inflation and price adjustment: Evidence from Norwegian consumer price data 1975-2004. Working Paper, Norges Bank. 
Table 1: Frequency of price changes

\begin{tabular}{|c|c|c|c|c|c|c|}
\hline & \multirow{2}{*}{$\begin{array}{c}\text { France } \\
\text { 2003-2011 } \\
\text { Mean }\end{array}$} & \multirow{2}{*}{$\begin{array}{c}\text { US } \\
\text { 1998-2005 } \\
\text { Mean }\end{array}$} & \multicolumn{2}{|c|}{$\begin{array}{c}\text { France } \\
\text { US weights }\end{array}$} & \multicolumn{2}{|c|}{$\begin{array}{c}\text { US } \\
\text { US weights }\end{array}$} \\
\hline & & & Mean & Median & Mean & Median \\
\hline \multicolumn{7}{|c|}{ Including sales, including substitutions } \\
\hline Frequency of price changes & 20.1 & 27.7 & 20.1 & 14.9 & 24.1 & 16.2 \\
\hline$\%$ of price increases & 60.2 & - & - & - & - & - \\
\hline \multicolumn{7}{|c|}{ Excluding sales, including substitutions } \\
\hline Frequency of price changes & 17.4 & 22.8 & 17.4 & 10.6 & 17.1 & 9.8 \\
\hline$\%$ of price increases & 62.3 & - & - & - & - & - \\
\hline \multicolumn{7}{|c|}{ Including sales, excluding substitutions } \\
\hline Frequency of price changes & 17.7 & 26.5 & 17.5 & 10.4 & 22.7 & 14.9 \\
\hline$\%$ of price increases & 59.9 & 55.1 & 58.0 & 54.5 & 53.6 & 54.4 \\
\hline \multicolumn{7}{|c|}{ Excluding sales, excluding substitutions } \\
\hline Frequency of price changes & 15.0 & 21.1 & 14.5 & 5.7 & 15.1 & 6.9 \\
\hline$\%$ of price increases & 63.5 & 59.1 & 62.4 & 84.3 & 60.9 & 76.0 \\
\hline$\%$ of seasonal sales & 0.7 & - & - & - & - & - \\
\hline$\%$ of promot. discounts & 1.7 & - & - & - & - & - \\
\hline$\%$ of prod. substitutions & 4.1 & 2.8 & - & - & - & - \\
\hline
\end{tabular}

Note: Frequency of price changes is the weighted proportion of price changes on all price records; Median frequency of price changes is calculated as the weighted median of product average frequencies of price changes; $\%$ of seasonal sales is the weighted proportion of regulated sales among all observations; $\%$ of promotional discounts is the weighted proportion of promotional discounts (excluding seasonal sales) among all observations; \% of product substitutions is the weighted proportion of product replacements among all price records; US results are from Nakamura and Steinsson [2008] and Nakamura and Steinsson [2010b]. In columns "US weights", we compute aggregate frequencies of price changes using product level frequencies for products available in US and French data set and using the US weight structure. 
Table 2: Frequency of price changes by sector

Food Manufacturing goods
Durables Clothing Other manuf.

\section{Durables Clothing Other manuf.}

\section{Including sales}

Frequency of price changes

$\%$ of price increases

20.7

22.2

24.9

14.4

77.1

8.2

56.4

48.3

50.0

63.4

60.7

77.6

\section{Excluding sales}

Frequency of price changes

$\%$ of price increases

17.1

16.5

12.5

12.5

77.0

8.0

58.0

48.9

55.1

65.9

60.7

78.4

$\%$ of seasonal sales

0.0

1.2

6.7

0.2

0.0

0.0

$\%$ of promot. discounts

3.0

4.5

2.8

1.7

0.1

0.2

$\%$ of prod. substitutions

2.2

16.2

4.1

0.7

2.0

Note: Frequency of price changes is the weighted proportion of price changes on all price records (including substitutions); \% of seasonal sales is the weighted proportion of regulated sales among all observations; \% of promotional discounts is the weighted proportion of promotional discounts (excluding seasonal sales) among all observations; \% of product substitutions is the weighted proportion of product replacements among all price records. 
Table 3: Size of price changes

Including sales Excluding sales

Price increases

Mean

12.8

7.9

Std

26.4

16.2

Lower quartile

2.0

1.9

Median

4.3

3.7

Higher quartile

10.9

7.6

Price decreases

Mean

$-11.5$

$-7.8$

Std

13.2

9.6

Lower quartile

$-16.1$

$-10.0$

Median

$-6.1$

$-4.4$

Higher quartile

$-2.3$

$-1.8$

$\%$ of absolute price change less than $2 \%$

23.7

27.4

$\%$ of absolute price change less than $1 \%$

11.2

Note: The statistics on the size of price changes are all weighted using CPI disaggregated weights on the period 2003-2011. Individual sizes of price changes are here calculated in percentage, and only non-zero price changes are considered (including substitutions). 
Table 4: Size of price changes: France - United States

\begin{tabular}{lcccc}
\hline & \multicolumn{2}{c}{$\begin{array}{c}\text { Mean } \\
\text { Median }\end{array}$} \\
& France & United States & France & United States \\
\hline Price increases & & & & \\
Including sales & 10.0 & 14.9 & 6.4 & 12.3 \\
Excluding sales & 6.0 & 9.2 & 5.2 & 8.0 \\
& & & & \\
Price decreases & & & & \\
Including sales & -13.4 & -18.5 & -8.9 & -15.3 \\
Excluding sales & -9.0 & -12.0 & -7.0 & -10.7 \\
& & & & \\
\hline
\end{tabular}

Note: The statistics on the size of price changes (in log-differences) are all weighted using US ELI disaggregated weights. Average and median price changes are first calculated at product level (on the period 1998-2005 for the US (Nakamura and Steinsson [2010b]) and on the period 2003-2011 for France) and then aggregate using US weight structure to obtain the average and median size of price changes. 
Table 5: Size of price changes by sector

\begin{tabular}{|c|c|c|c|c|c|c|c|c|}
\hline & \multicolumn{4}{|c|}{ Price increases } & \multicolumn{4}{|c|}{ Price decreases } \\
\hline & Mean & Q1 & Median & Q3 & Mean & Q1 & Median & Q3 \\
\hline \multicolumn{9}{|l|}{ Including sales } \\
\hline Food & 10.6 & 2.0 & 4.7 & 11.1 & -9.3 & -12.7 & -5.2 & -2.0 \\
\hline \multicolumn{9}{|l|}{ Manufacturing } \\
\hline Durables & 20.1 & 5.1 & 12.5 & 25.0 & -14.3 & -20.0 & -11.5 & -6.3 \\
\hline Clothing & 53.0 & 14.0 & 38.5 & 75.0 & -29.1 & -40.0 & -30.0 & -16.7 \\
\hline Other manuf. & 13.1 & 2.0 & 4.3 & 13.2 & -13.0 & -20.0 & -8.2 & -2.5 \\
\hline Energy & 3.8 & 1.7 & 3.1 & 5.0 & -3.9 & -5.2 & -2.9 & -1.5 \\
\hline Services & 9.0 & 2.1 & 4.0 & 9.0 & -12.8 & -17.7 & -9.3 & -3.8 \\
\hline \multicolumn{9}{|l|}{ Excluding sales } \\
\hline Food & 6.8 & 1.8 & 3.7 & 7.6 & -6.4 & -8.3 & -3.8 & -1.6 \\
\hline \multicolumn{9}{|l|}{ Manufacturing } \\
\hline Durables & 16.5 & 3.5 & 9.1 & 20.0 & -12.4 & -16.7 & -9.7 & -5.0 \\
\hline Clothing & 21.6 & 5.7 & 12.7 & 25.2 & -17.0 & -23.8 & -13.4 & -7.1 \\
\hline Other manuf. & 9.6 & 1.8 & 3.6 & 9.0 & -10.0 & -13.6 & -5.7 & -1.9 \\
\hline Energy & 3.8 & 1.7 & 3.0 & 5.0 & -3.9 & -5.2 & -2.9 & -1.5 \\
\hline Services & 8.5 & 2.1 & 3.8 & 8.5 & -12.3 & -16.7 & -8.8 & -3.4 \\
\hline
\end{tabular}

Note: The statistics on the size of price changes are all weighted using CPI disaggregated weights. Individual sizes of price changes are here calculated in percentage, and only non-zero price changes are considered (including substitutions). 
Table 6: Recomposing aggregate monthly inflation at the disaggregate product level

$\begin{array}{ccc}\text { Average monthly } & \text { Standard } & \text { Corr. with actual } \\ \text { inflation } & \text { Deviation } & \text { inflation (INSEE) }\end{array}$

Including sales and including subst. 0.185

0.454

0.826

Excluding sales and including subst.

0.185

0.366

0.700

Including sales and excluding subst.

0.150

0.341

0.871

Excluding sales and excluding subst.

0.154

0.268

0.742

Actual inflation (INSEE)

0.170

0.460

1

Note: We recompose monthly inflation rates at a disaggregate level of product (level 4 of the classification, 134 different products) using all individual price quotes under different hypotheses on sales and product replacements. We compute the monthly inflation rates for all 134 micro price indices recomposed with our micro data and for the corresponding 134 indices computed and published by INSEE. Then, we compute for all products, the average and the standard deviation of the monthly inflation rates and the coefficient of correlation between our recomposed inflation rate and the actual inflation rate at the product level. Finally, we compute the weighted median of average inflation, the weighted median of standard deviation and the weighted median of correlation coefficient across all 134 products. 
Table 7: Correlation between inflation, frequency and size of price changes

Correlation coefficients

(p-value)

Including sales Excluding sales

\begin{tabular}{lcc}
\hline Frequency of price changes & -0.22 & 0.56 \\
& $(0.03)$ & $(0.00)$ \\
Freq. increases & 0.02 & 0.76 \\
& $(0.81)$ & $(0.00)$ \\
Freq. decreases & -0.60 & -0.20 \\
& $(0.00)$ & $(0.05)$ \\
Size of price changes & 0.97 & 0.73 \\
Size increases & $(0.00)$ & $(0.00)$ \\
& 0.57 & -0.38 \\
Size decreases & $(0.00)$ & $(0.00)$ \\
& 0.52 & 0.16 \\
& $(0.00)$ & $(0.13)$ \\
\hline
\end{tabular}

Note: We recompose monthly inflation rates using all individual price quotes (excluding energy) and under different hypotheses on sales (including substitutions). We compute the correlation coefficients between the recomposed monthly inflation rate and the frequency/size of price

changes/increases/decreases. Size of price changes are here calculated as the weighted average of log differences. 
Table 8: Probability and size of sales on inflation, unemployment and recession

\begin{tabular}{lcccc}
\hline & \multicolumn{2}{c}{ Sales } & & \multicolumn{2}{c}{ Excluding seasonal sales } \\
& Probability & Size & Probability & Size \\
& & & & \\
\hline \multirow{2}{*}{ Cumulative inflation } & $-0.092^{* * *}$ & -0.003 & $-0.069^{* * *}$ & $0.039^{* * *}$ \\
& $(0.002)$ & $(0.011)$ & $(0.002)$ & $(0.012)$ \\
Unemployment & $0.195^{* *}$ & $-0.510^{*}$ & $0.121^{*}$ & $-0.456^{*}$ \\
& $(0.083)$ & $(0.268)$ & $(0.062)$ & $(0.266)$ \\
Great Recession & $0.223^{* *}$ & 0.151 & $-0.150^{*}$ & 0.372 \\
& $(0.10)$ & $(0.338)$ & $(0.077)$ & $(0.339)$ \\
\hline N observations & $2,894,231$ & 170,163 & $2,894,231$ & 115,513
\end{tabular}

Note: The sample excludes service and energy sectors, in which the incidence of sales is marginal. Columns 1 and 3 of the table reports marginal effects obtained from Probit models where the endogenous variable is a dummy variable equal to one if a product is on sale or on promotional discount. Columns 2 and 4 reports parameter estimates obtained from OLS regressions where the endogenous variable is the size of price decrease during sales. "Cum. inflation" is the cumulative product-level inflation rate (at the 4-digit product level) since the last price change in a given outlet $i$. The product-level inflation rate is computed using individual price data excluding sales but including substitutions. "Unemployment" is the unemployment rate in France (source Eurostat). "Great Recession" is a dummy variable equal to 1 when France was in recession, we use the datation of CEPR Euro Area Business Cycle for France (Jan 2008 to June 2009). Year, month and product (5-digit product level) controls are included. ${ }^{* * *}$ significant at $1 \%, * *$ significant at $5 \%,{ }^{*}$ significant at $10 \%$. Standard deviations of estimates are reported in brackets. 
Table 9: Probability and size of price changes at product substitutions on inflation, unemployment and recession

\begin{tabular}{lcccc}
\hline & \multicolumn{2}{c}{ Price increases } & \multicolumn{2}{c}{ Price decreases } \\
& Probability & Size & Probability & Size \\
& & & & \\
\hline \multirow{3}{*}{ Cumulative inflation } & $-0.024^{* * *}$ & $0.033^{*}$ & $-0.047^{* * *}$ & $0.122^{* * *}$ \\
& $(0.002)$ & $(0.019)$ & $(0.002)$ & $(0.019)$ \\
Unemployment & $0.082^{* * *}$ & 0.029 & $0.160^{* * *}$ & -0.053 \\
& $(0.030)$ & $(0.234)$ & $(0.028)$ & $(0.262$ \\
Great Recession & 0.020 & 0.467 & $0.109^{* * *}$ & -0.244 \\
& $(0.042)$ & $(0.326)$ & $(0.039)$ & $(0.359)$ \\
\hline N observations & $4,515,950$ & 132,571 & $4,515,950$ & 112,925 \\
\hline
\end{tabular}

Note: The sample includes all sectors; we consider price changes excluding sales. Columns 1 and 3 of the table reports marginal effects obtained from Probit models where the endogenous variable is a dummy variable equal to one if there is a product substitution and a price change. Columns 2 and 4 reports parameter estimates obtained from OLS regressions where the endogenous variable is the size of price decrease or increase when the product is replaced. "Cum. inflation" is the cumulative product-level inflation rate (at the 4-digit product level) since the last price change in a given outlet $i$. The product-level inflation rate is computed using individual price data excluding sales but including substitutions. "Unemployment" is the unemployment rate in France (source Eurostat). "Great Recession" is a dummy variable equal to 1 when France was in recession, we use the datation of CEPR Euro Area Business Cycle for France (Jan 2008 to June 2009). Year, month and product (5-digit product level) controls are included. $* * *$ significant at $1 \%, * *$ significant at $5 \%,{ }^{*}$ significant at $10 \%$. Standard deviations of estimates are reported in brackets. 
Table 10: Probability and size of price changes on inflation, unemployment and recession

\begin{tabular}{lcccc}
\hline & \multicolumn{2}{c}{ Price increases } & \multicolumn{2}{c}{ Price decreases } \\
& Probability & Size & Probability & Size \\
& & & & \\
\hline \multirow{2}{*}{ Cumulative inflation } & $0.290^{* * *}$ & $0.074^{* * *}$ & $-0.194^{* * *}$ & $0.254^{* * *}$ \\
& $(0.004)$ & $(0.002)$ & $(0.003)$ & $(0.013)$ \\
Unemployment & $-0.906^{* * *}$ & $-0.222^{* * *}$ & $0.533^{* * *}$ & -0.089 \\
& $(0.038)$ & $(0.010)$ & $(0.032)$ & $(0.083$ \\
Great Recession & $0.482^{* * *}$ & $0.133^{* * *}$ & $0.266^{* * *}$ & $-0.202^{*}$ \\
& $(0.053)$ & $(0.014)$ & $(0.045)$ & $(0.104)$ \\
\hline N observations & $8,022,198$ & 682,295 & $8,022,198$ & 477,654 \\
\hline
\end{tabular}

Note: The sample excludes prices of the energy sector and consist of price changes excluding sales and including substitutions. The table reports marginal effects obtained from the estimation of Tobit models. "Cum. inflation" is the cumulative product-level inflation rate (at the 4-digit product level) since the last price change in a given outlet $i$. The product-level inflation rate is computed using individual price data excluding sales but including substitutions. "Unemployment" is the unemployment rate in France (source Eurostat). "Great Recession" is a dummy variable equal to 1 when France was in recession, we use the datation of CEPR Euro Area Business Cycle for France (Jan 2008 to June 2009). Year, month and product (5-digit product level) controls are included. significant at $1 \%, * *$ significant at $5 \%, *$ significant at $10 \%$. Standard deviations of estimates are reported in brackets. 
Figure 1: Distribution of non-zero price changes

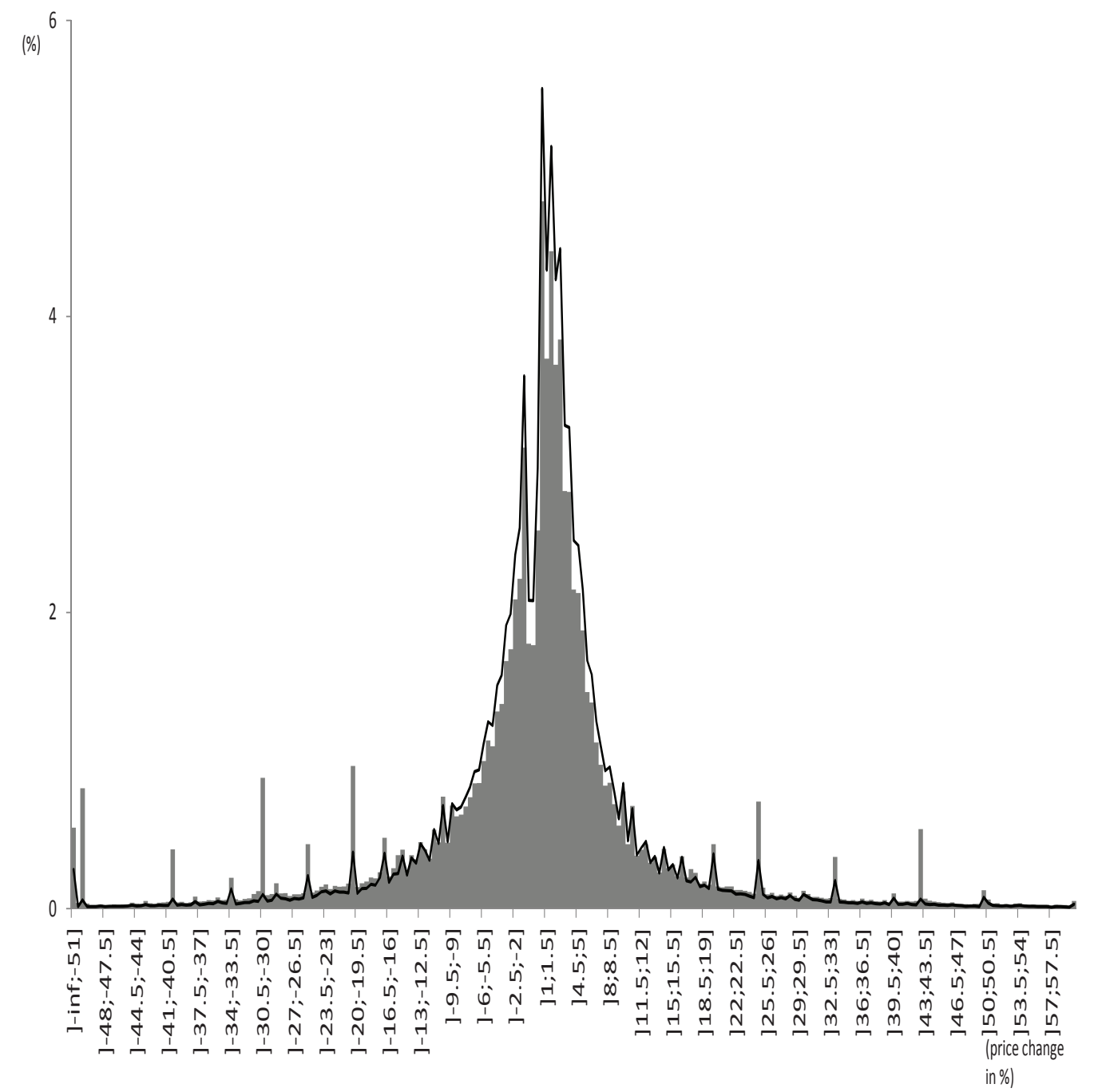

Note: Individual sizes of price changes are here calculated in percentage, only non-zero price changes are considered, and product substitutions are considered as price changes; the distribution is weighted using CPI disaggregated weights on the period 2003-2011. Gray histogram: price changes related to sales are included. Black solid line: price changes related to sales are excluded (using INSEE sales flag). 
Figure 2: Contributions of the frequency and of the size of price changes to inflation Including product replacements

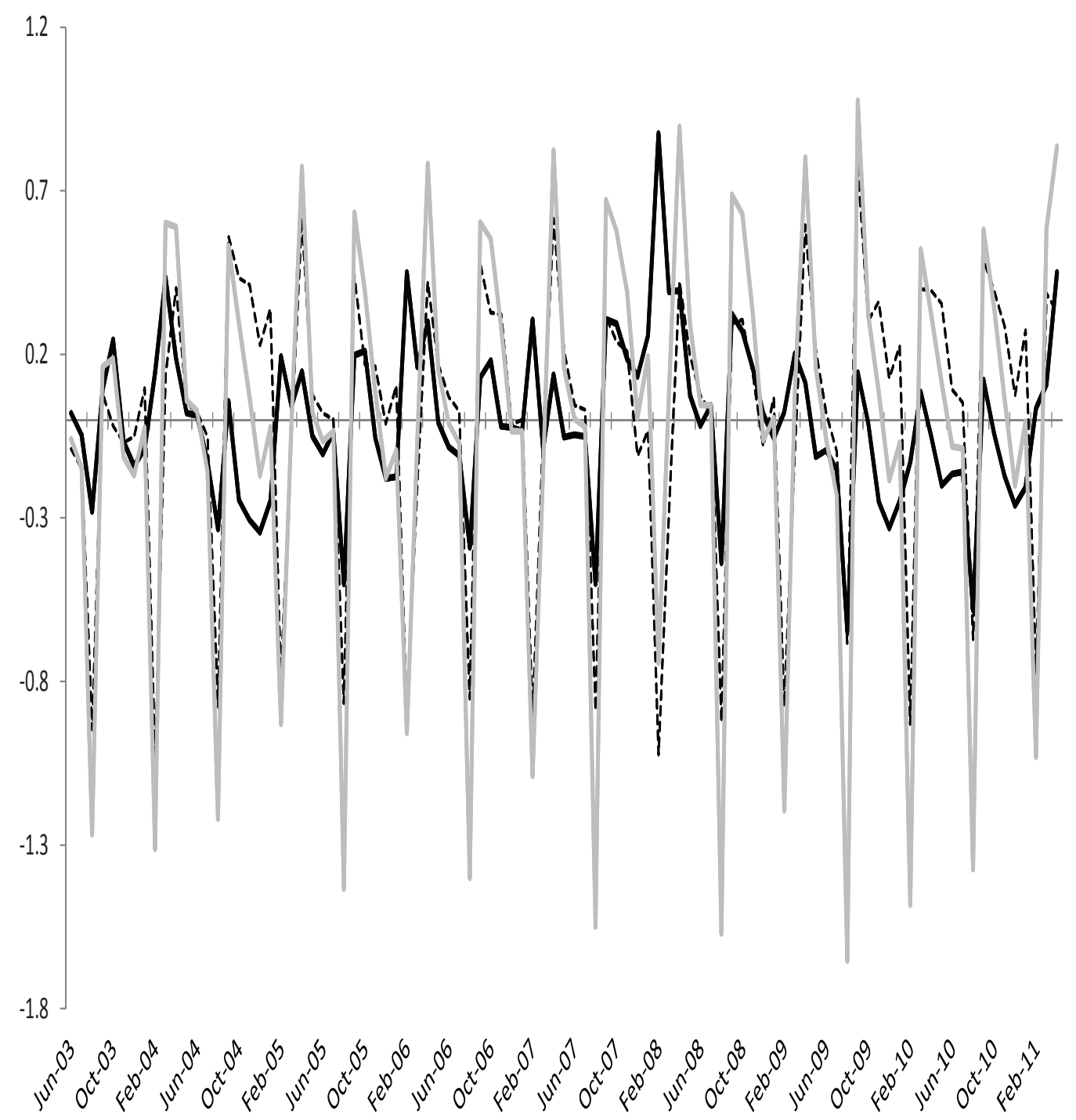

Note: Gray solid line: deviations of the monthly rate of inflation from its average over time (excluding energy), product replacements and sales included. Black solid line: contribution of the frequencies of price increases and of price decreases to the deviations of monthly inflation over time. Black dashed line: contribution of the average sizes of price increases and of price decreases to the deviations of monthly inflation over time. 
Figure 3: Contributions of the frequency and of the size of price changes to inflation Non-sales prices

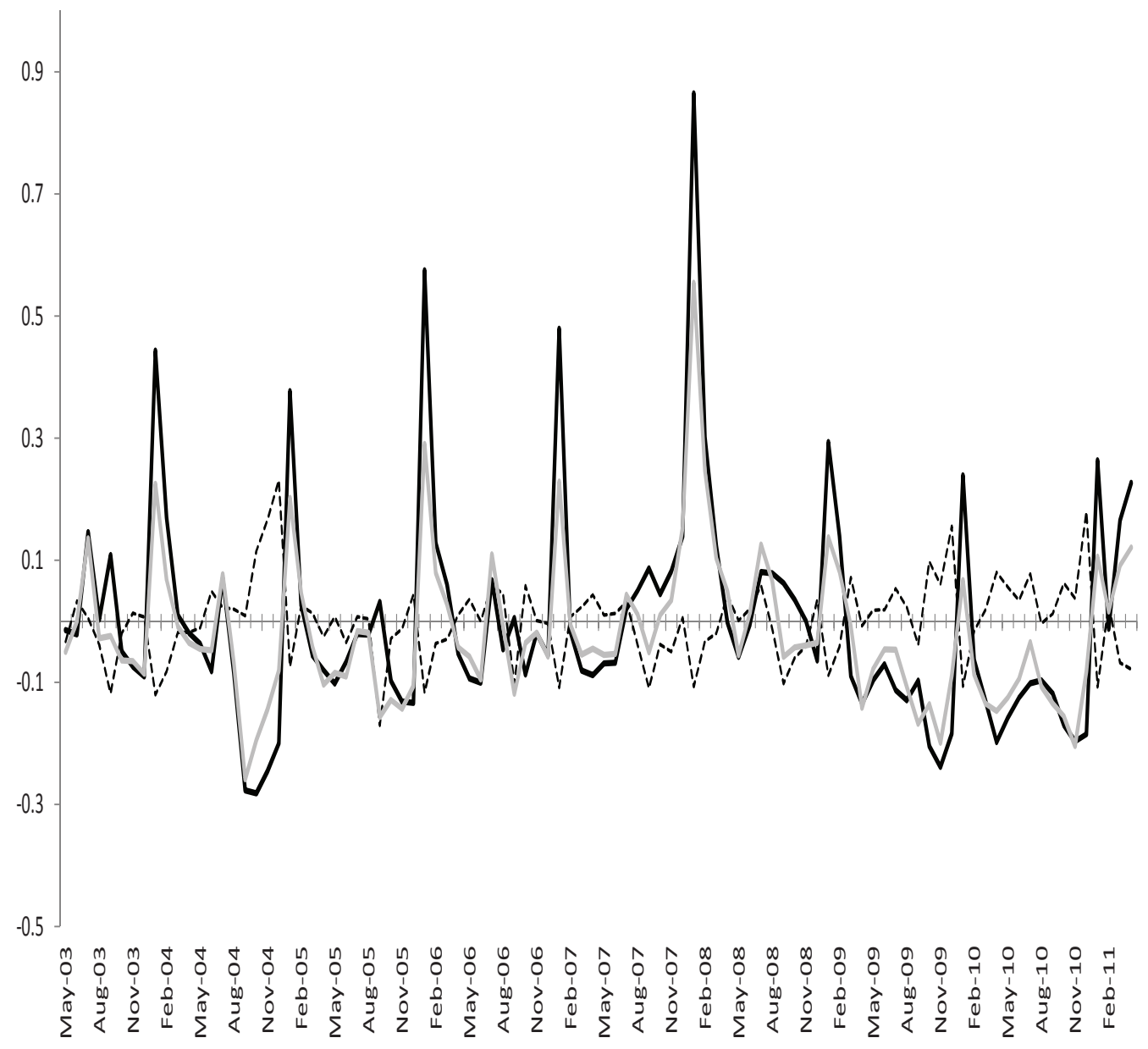

Note: Gray solid line: deviations of the monthly rate of inflation from its average over time (excluding energy), product replacements are included and sales are excluded. Black solid line: contribution of the frequencies of price increases and of price decreases (excluding sales) to the deviations of monthly inflation over time. Black dashed line: contribution of the average sizes of price increases and of price decreases (excluding sales) to the deviations of monthly inflation over time. 
Figure 4: Seasonality of the frequency of price changes

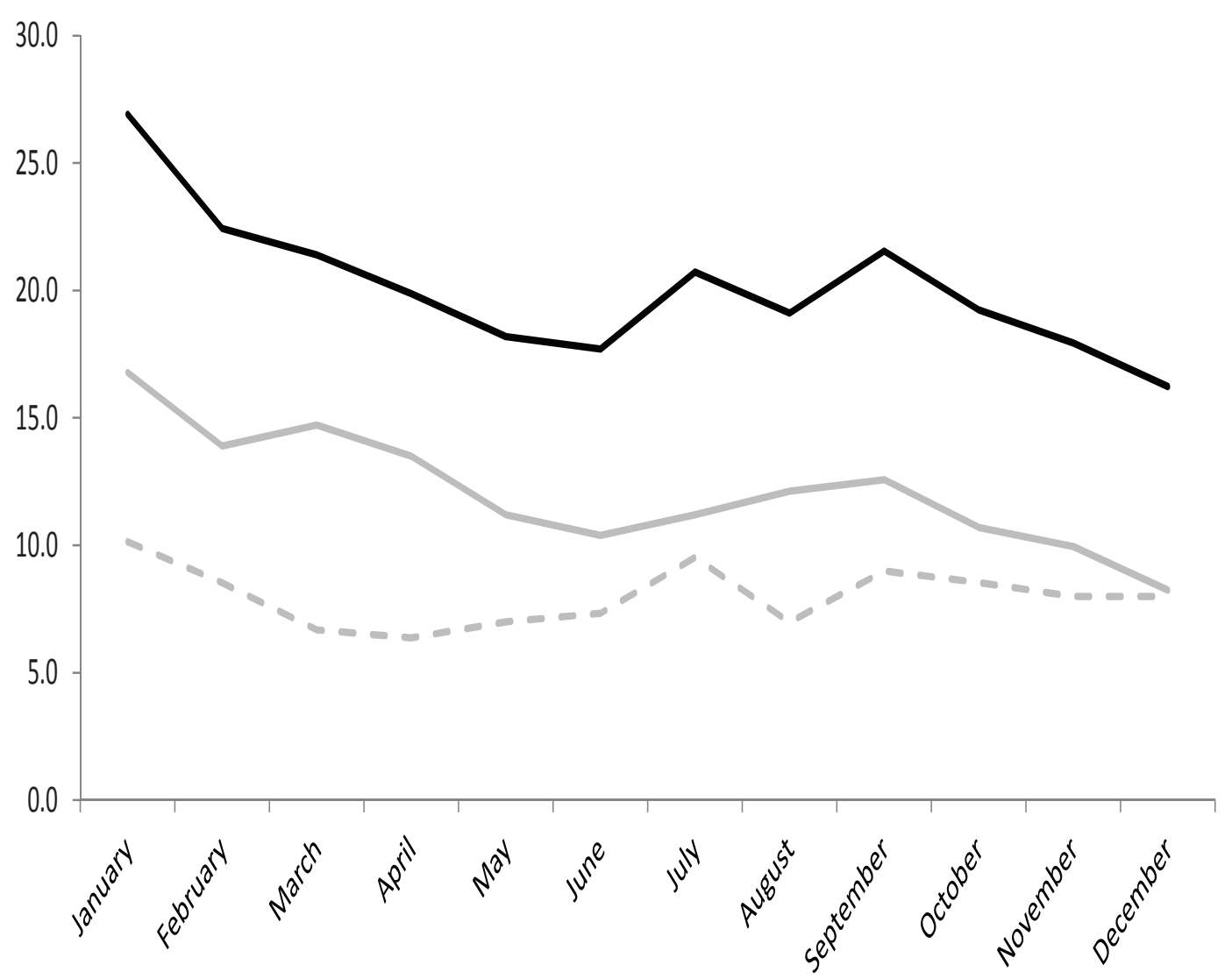

Note: Price changes related to product replacements are considered as price changes. Black solid line: frequency of price changes by month. Gray solid line: frequency of price increases by month. Gray dashed line: frequency of price decreases by month. 
Figure 5: Seasonality of the frequency of price changes - by sector

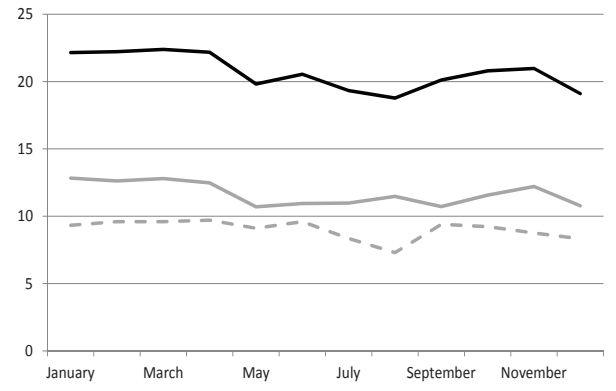

(a) Food

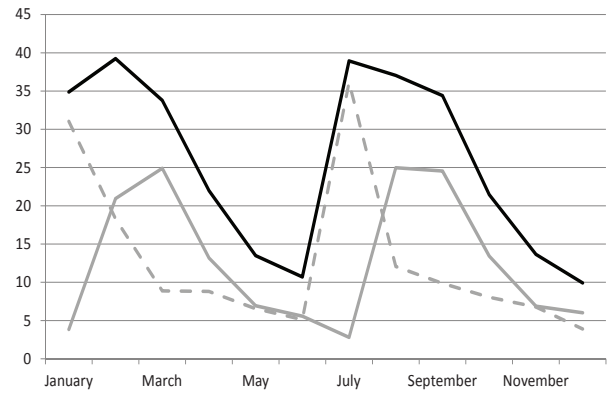

(c) Clothing

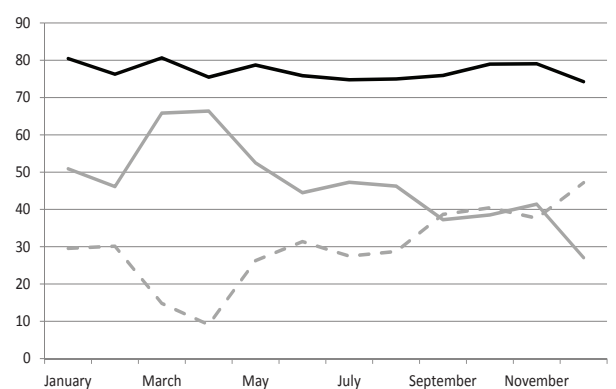

(e) Energy

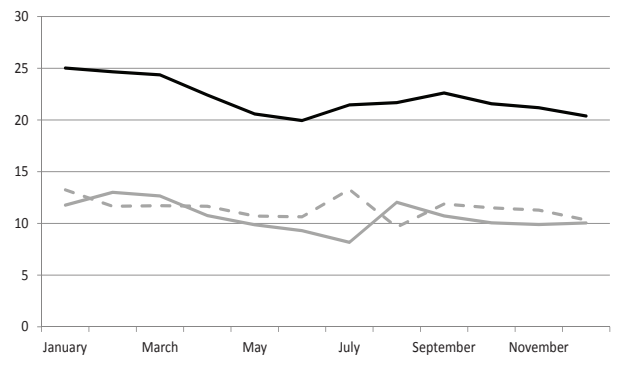

(b) Durables

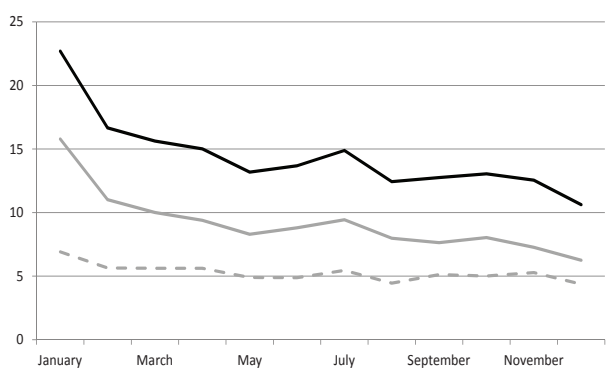

(d) Other Manuf.

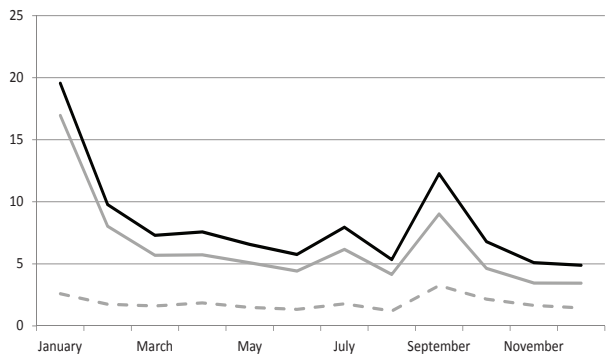

(f) Services

Price changes related to product replacements are considered as price changes. Black solid line: frequency of price changes by month. Gray solid line: frequency of price increases by month. Gray dashed line: frequency of price decreases by month. 
Figure 6: Seasonality of the frequency of price changes - Impact of sales

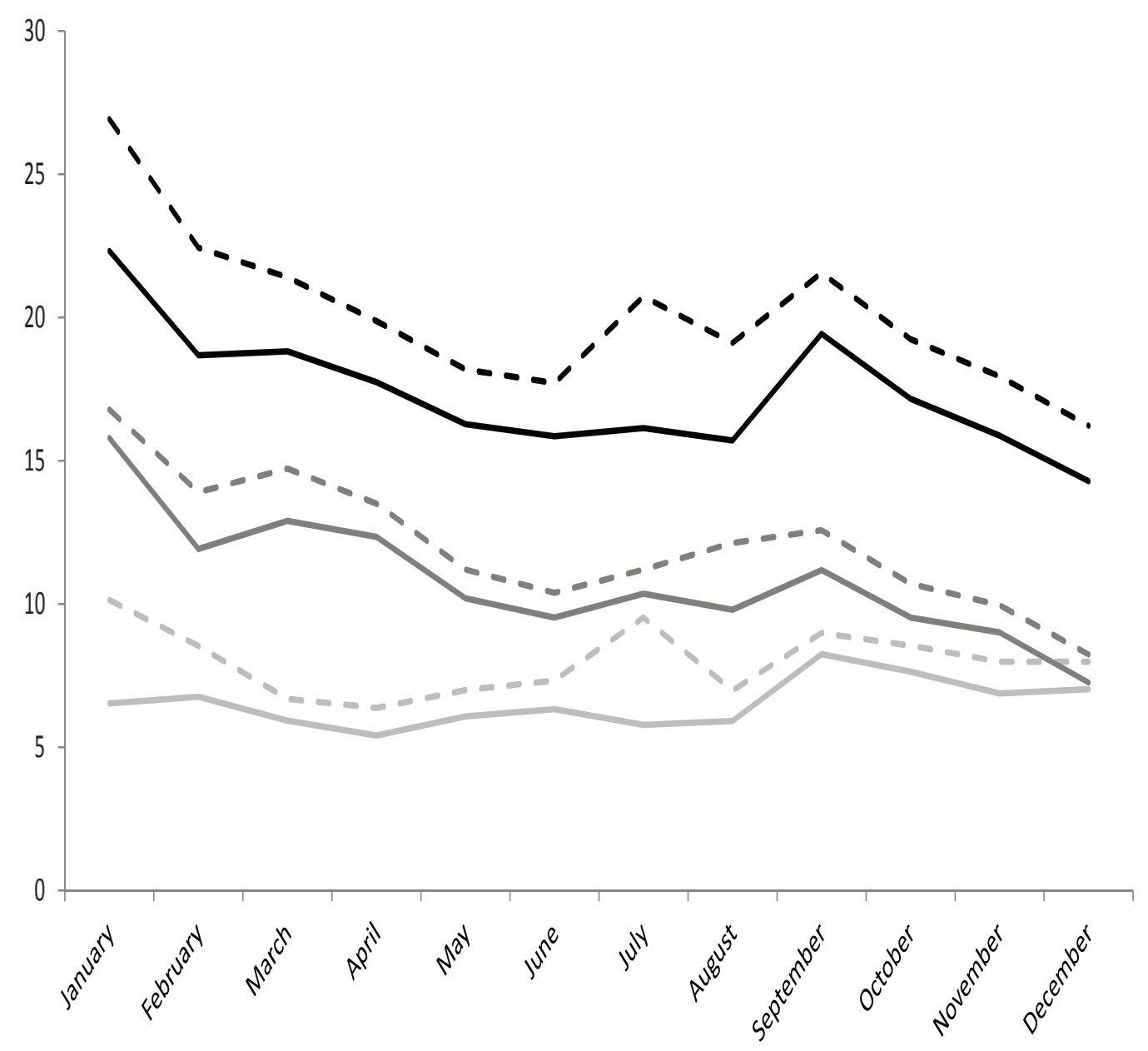

Note: Black solid line: frequency of price changes. Dark gray line: frequency of price increases. Light gray line: frequency of price decreases. Dashed lines: frequencies are calculated in the case including price changes related to sales and product replacements. Solid lines: frequencies are calculated in the case excluding price changes related to sales but including product replacements. 
Figure 7: Seasonality of the size of price changes

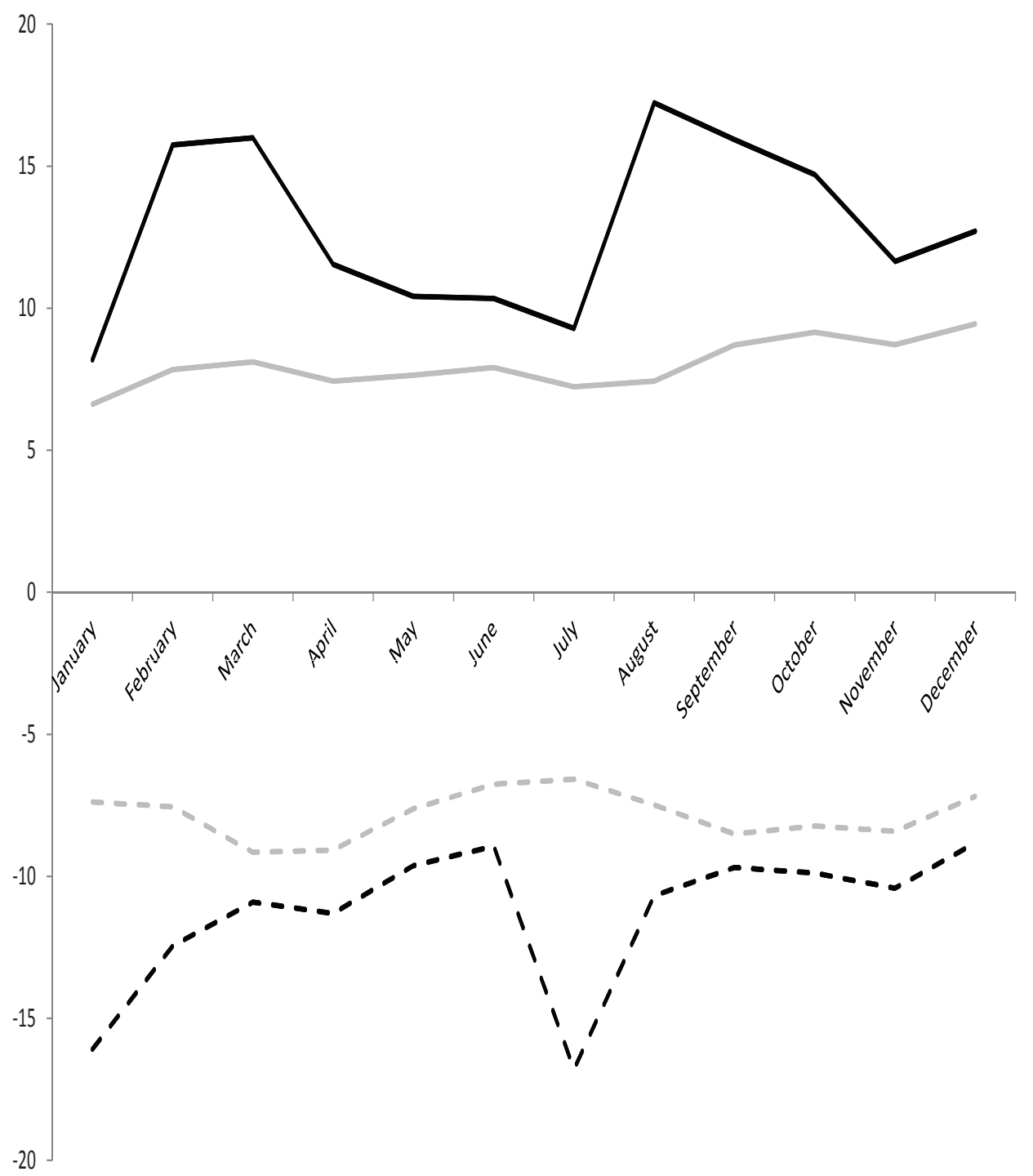

Note: Dashed lines: size of price decreases and solid lines: size of price increases. Black lines: weighted average size of price increases or decreases (in percent) including sales. Gray lines: weighted average size of price increases or decreases (in percent) excluding sales. Product substitutions are included. 
Figure 8: Overall inflation and overall inflation excluding energy (in \%)

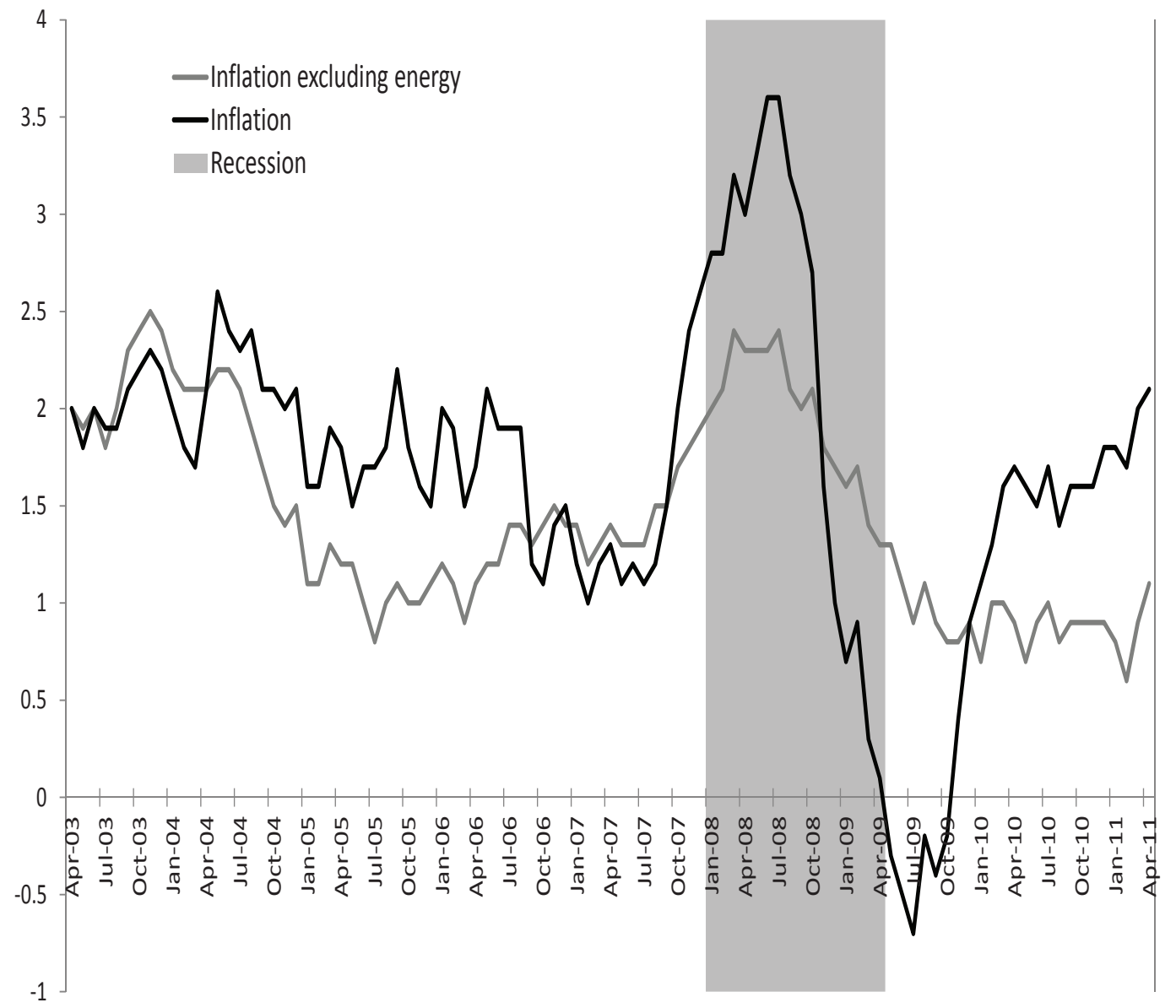

Note: Inflation rates are calculated as annual variations of CPI (overall) and CPI (overall excluding energy). Recession means that quarterly growth of GDP is negative during at least 2 quarters. 
Figure 9: Frequency of price changes, increases and decreases over time

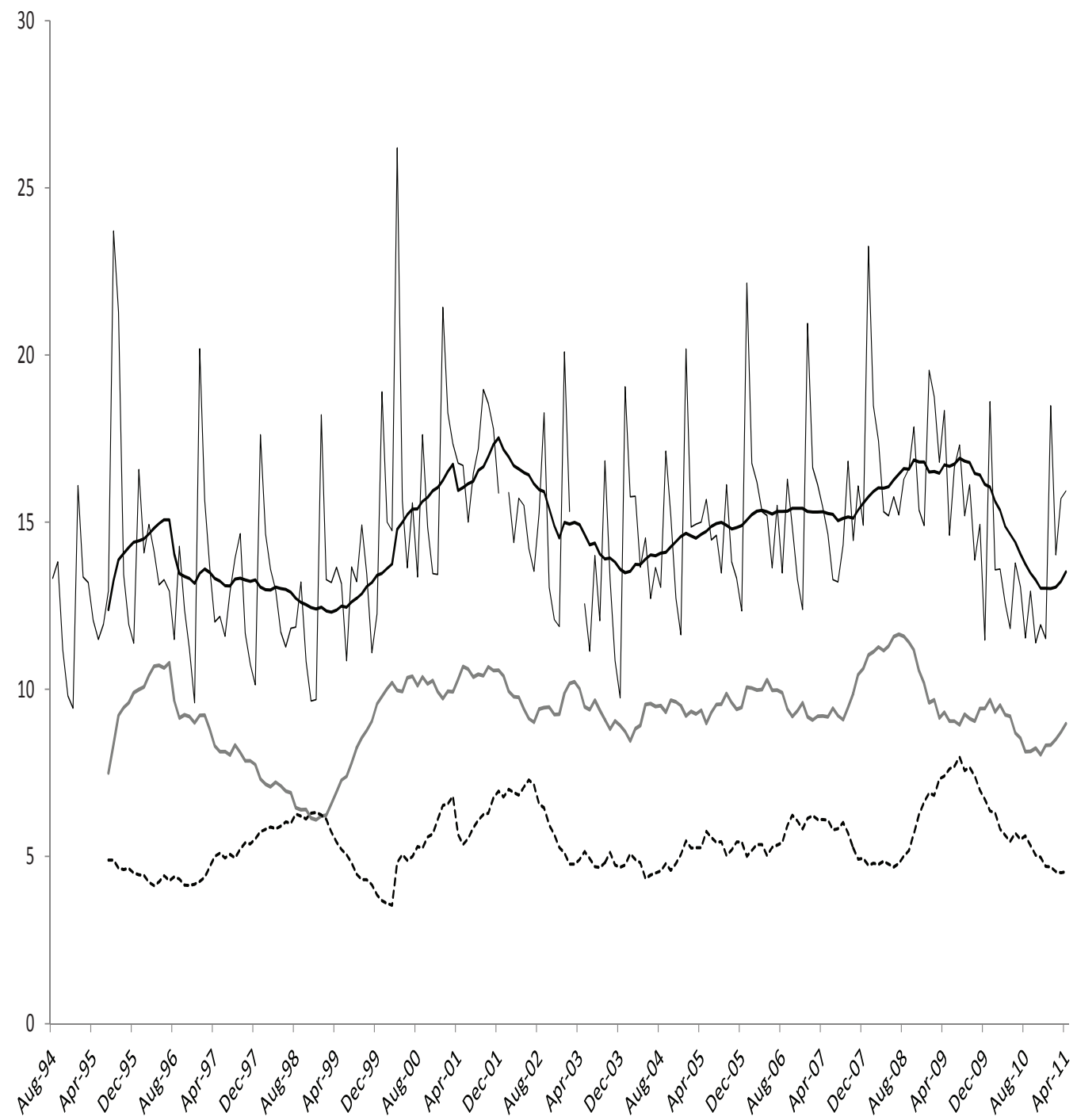

Note: Black lines: Monthly weighted frequency of price changes and its moving average over 12 months. Gray line: Moving average (over 12 months) of the monthly weighted frequency of price increases. Black dashed line: Moving average (over 12 months) of the monthly weighted frequency of price decreases. Price changes due to product replacements and sales are excluded. Numbers for the period July 1994-February 2003 are coming from results of Baudry et al. [2007], January 2002 is excluded. 
Figure 10: Average and median size of price increases and decreases over time

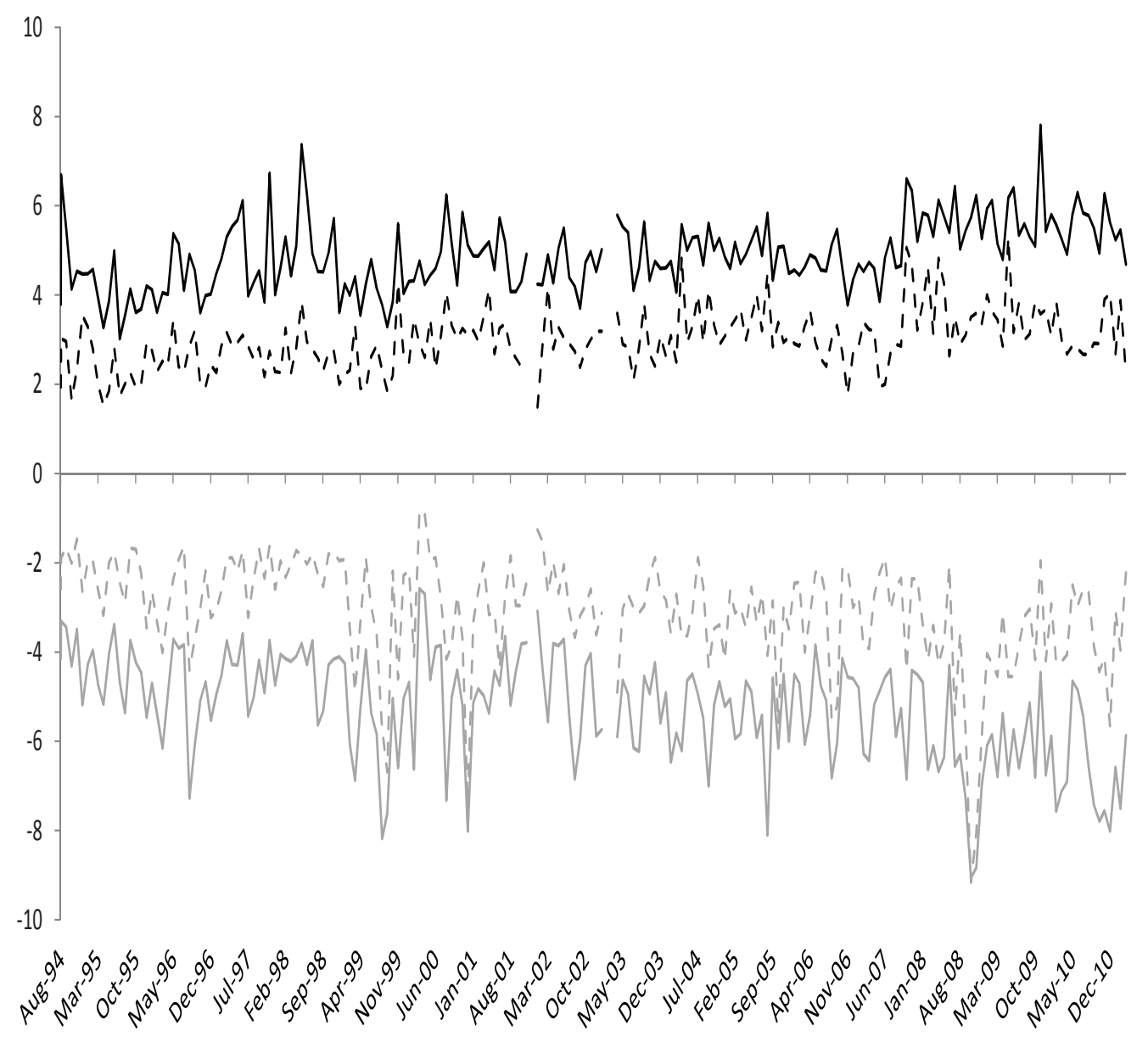

Note: Black solid line: Average weighted size of price increases. Black dashed line: median weighted size of price increases. Gray solid line: Average weighted size of price decreases. Dashed gray line: median weighted size of price decreases. Price changes due to product replacements and sales are excluded. Numbers for the period July 1994-February 2003 are coming from results of Baudry et al. [2007], January 2002 is excluded. 


\section{Appendix (Not intended for publication)}

\section{Data treatment}

We here describe the main preliminary data treatments.

First, to take into account potential variation in the quantity corresponding to a price record, we calculated the unit price of items dividing the price by the quantity. Some changes in the unit of measurement (or more generally measurement error) may affect quantity. We correct quantities for measurement errors when quantity changes are greater than a factor 5 and apply a carry-forward procedure to replace errors in quantities. This procedure corrects less than 100 observations in the data set.

Second, we correct for measurement errors in price changes. We consider that unit price change greater than a factor 5 are measurement errors and we exclude them from the sample. We also test a less stringent assumption, which is considering as measurement errors only unit price changes greater than a factor 10 (as in Klenow and Kryvtsov [2008]), but most of results remain very similar (see Table A).

Finally, we deal with imputed prices. Indeed, the INSEE procedure of recording individual prices for a given individual product does not allow missing values. However, in some cases, the price of a product cannot be observed. The value recorded is then the outcome of an imputation procedure (see Turvey [1999]) and it is labelled as "pseudoprice". The other two price labels are "regular price" and "seasonal sale or temporary promotional discount". Failure to observe a price can result from a variety of situations, calling for different procedures to assign a pseudo price. Some products are seasonal by nature and their price is not posted all year round (e.g. ski gloves may not be sold during summer). These pseudo prices account for $7.7 \%$ of price quotes, and are mainly in the clothing sector. INSEE generally implements a carry-forward procedure for those prices: the unobserved price of the item is assumed to be the same as when it was last observed. In our study, we have removed from our sample prices of out-of-season items and compare prices across missing observations. Table A compares results obtained when we exclude or include prices of out-of-season items.

There are other reasons why prices are not observed: (i) some prices fail to be observed because the prices of some products, mainly durable goods, are collected only at a quarterly frequency ( $0.4 \%$ of records); (ii) a product is temporarily absent in an outlet, or that an outlet is temporarily closed or that a collector absent (about $6.5 \%$ of price quotes). In that case, the INSEE evaluates the missing price according either to the carry-forward procedure, or preferably by using extrapolation or by computing a replace- 
ment price. The extrapolation procedure relies on adjusting the previous price by using the rate of change of the price index for the product in the same geographical area. We replaced those pseudo prices using a carry-forward procedure: whenever a price is not available at date $t$, then we replace the pseudo price with the last normal price observed.

One possible case where our procedure might create a downward bias on the estimated frequency of price changes is when the product was unavailable on the precise day the collector visited the outlet, but was present on other days in the month with a price different from $P$, say $P^{\prime}$. We can however reasonably think that this bias is small.

\section{Sales identification}

There are alternative ways to identify sales. The most direct one is using the INSEE sale flag to identify sales (i.e. seasonal sales and promotional discounts). To remove price changes associated with sales, we replace prices of products on sales by the last regular price. This procedure has been used as baseline procedure to remove sales prices in most of empirical papers dealing with price rigidity (Bils and Klenow [2004], Klenow and Kryvtsov [2008] or Nakamura and Steinsson [2008]). Alternative procedures are used in the literature to test robustness of the results to the definition of temporary price changes. We here follow the definition of $\mathrm{V}$-shaped sales proposed by Nakamura and Steinsson [2008] (supplement material, appendix A). We consider two types of sales filters. First, a symmetric V-shaped sales filter aims at removing price patterns in which a price decreases and then goes back to the original price within a short period (without going above the original price) (sales filter B in Nakamura and Steinsson [2008]). We can allow this period when price returns to the original price to be very short (one month) or longer (e.g. five months). We here consider three possibilities: 1 month, 3 months and 5 months. It means that we allow the price to come back to the regular price some months after the price decrease. If the price does not return to the original price, we consider that the price change is a regular price change. A second type of filter is an asymmetric $\mathrm{V}$-shaped sales filter removing price patterns in which a sales price is followed by a change in the regular price (sales filter A in Nakamura and Steinsson [2008]).

\section{Weights}

There are two possibilities for weighting statistics. The first one (our baseline) consists in using the average over time of CPI category weights. This allows to control for compositional changes of the CPI over time. Nakamura and Steinsson [2008] for instance use time invariant weights. The alternative procedure is to use CPI category weights that 
vary over time. This would allow to be closer to the official CPI and to obtain statistics for a representative basket of goods. This strategy is for instance followed by Klenow and Kryvtsov [2008] to compute average weighted statistics. We computed statistics with time varying weights as a robustness check and results were similar.

\section{More details on the Tobit model}

We here present more details on our Tobit model. In this model, a first equation models the determinants of the probability of price changes, while a second equation explains the size of price changes. Equation (6) models the price change decision:

$$
y_{i t}^{*}=\alpha+\beta \pi_{j t}+\gamma x_{t}+\mu_{m}+\mu_{y}+\theta_{p}+u_{i t}
$$

where $i$ denotes the product-outlet pair, $t$ is the date, $y_{i t}^{*}$ is an unobservable latent variable driving the decision of price increase (or decrease), $\pi_{j t}$ is the cumulative inflation rate at the 4-digit product level since the last price change of outlet $i$. The inflation rate is calculated using our micro prices excluding sales and including product substitutions. $x_{t}$ is a vector of variables capturing business conditions. Our benchmark specification includes in $x_{t}$ the unemployment rate and a dummy for the Great Recession. ${ }^{37} \mu_{y}, \mu_{m}$ and $\theta_{p}$ are dummy variables respectively for the year, the month of the year, and for the product at the 5-digit level. $u_{i t}$ is a Gaussian, mean-zero, i.i.d shock. When $y_{i t}^{*}>0$, then price in outlet $i$ at date $t$ increases (or decreases, in the case of the model for price decreases). When $y_{i t}^{*}<0$ then price in outlet $i$ at date $t$ remains unchanged. We observe a variable equal to one when a price is increased (resp. decreased) and zero otherwise. Using equation (6), we explain the probability of price changes. When prices are increased (or decreased), i.e. when $y_{i t}^{*}>0$, a second equation accounts for the size of price change controlling for the selection effect, i.e. the fact that the determinants of the first stage regression did actually trigger a price change:

$$
d p_{i t}^{*}=a+b \pi_{i t}+c x_{t}+d_{y}+e_{p}+\epsilon_{i t}
$$

where $d p_{i t}^{*}$ is an unobservable latent variable for the size of price increase (or decrease). If $y_{i t}^{*}>0$, the size of price change is given by $d p_{i t}^{*}=d p_{i t}$, while $d p_{i t}=0$ is observed whenever $y_{i t}^{*}<0$. For identification reasons, the monthly dummies included in the price change decision equation are excluded from equation (7) explaining the size of price changes. We assume that the month of the year is relevant for outlets in the timing of

\footnotetext{
${ }^{37}$ As there is no benchmark business cycle dating for France and the euro area cycle is well correlated with that of the French economy, we use a dummy for recession dates as identified by the CEPR.
} 
their price decisions (because of annual contracts, holidays...), but that it has no specific effect on the size of price changes. $\epsilon_{i t}$ is a Gaussian i.i.d shock correlated to $u_{i t}$. We estimate this model using a maximum-likelihood procedure. 


\section{Appendix Tables and Figures}

\section{A.1 Data treatment and sale filters}

Figure A: Three different hypotheses on product substitution and price trajectory

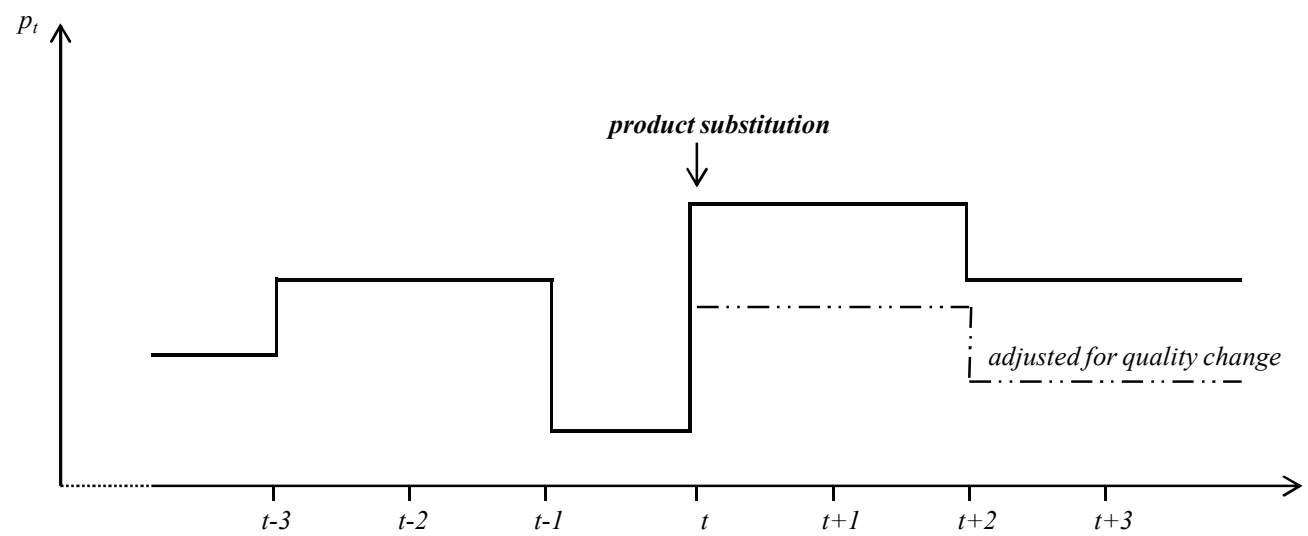

Case I:

price trajectory 1

price trajectory 2

$\Delta p_{t}$ excluded

Case II:

price trajectory 1

$\Delta p_{t}$ included

Case III:

price trajectory 1

$\Delta p_{t}$ included and adjusted for quality change 
Table A: Frequency and size of price changes - Data treatment

Excluding out-of-season items Including out-of-season items

$\begin{array}{llll}\text { Factor } 5 & \text { Factor } 10 & \text { Factor } 5 & \text { Factor } 10\end{array}$

Including sales, excluding substitutions

Frequency of price changes $\quad 17.7$

Size of price increases $\quad 8.9$

8.9
-10.7

17.7

17.2

17.2

Size of price decreases

8.9

9.2

9.3

$-10.7$

$-9.7$

$-9.7$

Excluding sales, excluding substitutions

Frequency of price changes $\quad 15.0$

Size of price increases $\quad 5.2$

14.7

14.7

Size of price decreases

$-5.8$

5.2

5.1

$-5.7$

$-5.7$

Including sales, including substitutions

Frequency of price changes $\quad 20.1$

Size of price increases $\quad 12.8$

20.1

19.3

19.3

Size of price decreases

$-11.5$

13.0

11.5

11.6

$-11.5$

$-10.6$

$-10.6$

Excluding sales, including substitutions

Frequency of price changes $\quad 17.4$

Size of price increases

7.9

17.4

16.8

16.8

Size of price decreases

$-7.8$

7.8

7.6

7.7

$-7.9$

$-7.5$

$-7.5$

Note: Frequency of price changes is the weighted proportion of price changes on all price records and the mean size of price changes is the weighted average of individual sizes of price changes (in percentage, and excluding zero price changes). We consider alternative choices of data treatment:

"Excluding out-of-season items", we remove all missing observations for product that are mentioned "out of season" by INSEE (e.g. gloves in summer), but compare prices across missing observations, whereas "Including out-of-season items" we follow a carry-forward procedure and assume that the price is the same as when it was last observed. We also present result for alternative assumptions for what we consider as outliers: "Factor 5" we exclude price changes greater than a factor 5, whereas "Factor 10" we exclude price changes greater than a factor 10 (as done by Klenow and Kryvtsov [2008]. 
Table B: Frequency of price changes for sales filters

\section{Excluding substitutions Including substitutions}

Including sales

Sales flag

Symmetric filter (5-month window) Asymmetric filter (1-month window) Asymmetric filter (3-month window) Asymmetric filter (5-month window)
17.7

15.0

14.0

14.3

13.7

13.4
20.1

17.4

16.1

16.0

15.4

15.1

Note: Frequency of price changes is the weighted proportion of price changes on all price records. The table presents results for alternative procedures to filter out V-shaped sales. "Sale flag": we use information provided by INSEE to remove price changes related to sales; "Symmetric filter" removes symmetric V-shaped sales, whereas "Asymmetric filter" allows for asymmetric V-shaped sales (see description of filters in Appendix). We consider different windows (between 1 and 5 months) for return to the original price. In all cases, clearance sales are removed. 
Table C: Size of price changes for sales filters

\section{Excluding substitutions Including substitutions}

Increases Decreases Increases Decreases

\begin{tabular}{lcccc}
\hline & & & & \\
Including sales & 8.9 & -10.7 & 12.8 & -11.5 \\
Sales flag & 5.2 & -5.8 & 7.9 & -7.8 \\
Symmetric filter (5-month window) & 5.8 & -9.0 & 10.2 & -9.7 \\
Asymmetric filter (1-month window) & 5.9 & -8.8 & 8.4 & -8.3 \\
Asymmetric filter (3-month window) & 5.5 & -8.6 & 8.1 & -8.1 \\
Asymmetric filter (5-month window) & 5.4 & -8.7 & 8.2 & -8.2 \\
& & & & \\
\hline
\end{tabular}

Note: The mean size of price changes is the weighted average of individual sizes of price changes (in percentage, and excluding zero price changes) using CPI disaggregated weights on the period 2003-2011. The table presents results for alternative procedures to filter out V-shaped sales. "Sale flag": we use information provided by INSEE to remove price changes related to sales; "Symmetric filter" removes symmetric V-shaped sales, whereas "Asymmetric filter" allows for asymmetric V-shaped sales (see description of filters in Appendix). We consider different windows (between 1 and 5 months) for return to the original price. In all cases, clearance sales are removed. 
Figure B: Distribution of non-zero price changes - alternative sales filters

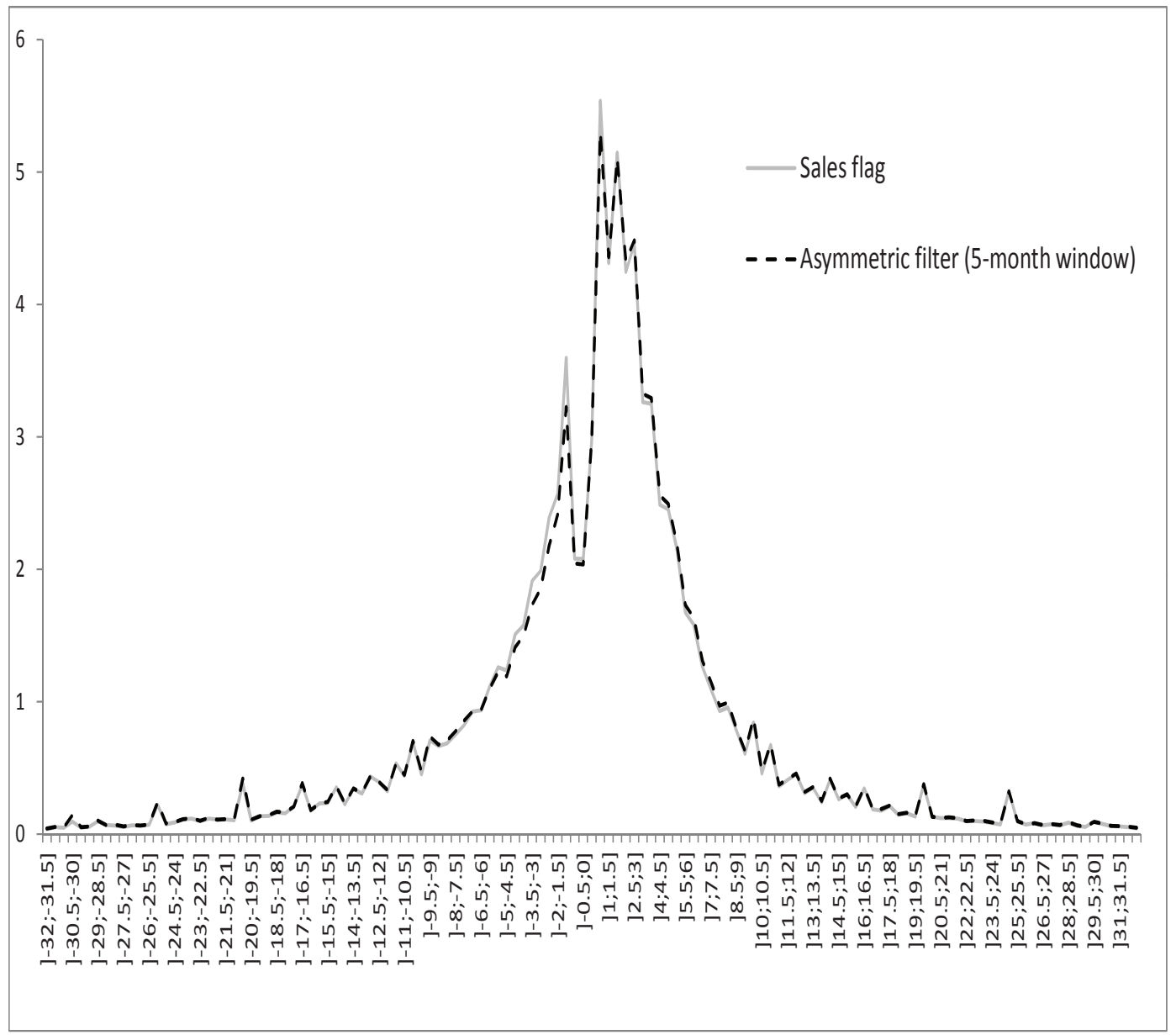

Note: Individual sizes of price changes are here calculated in percentage, only non-zero price changes are considered, and product substitutions are considered as price changes; the distribution is weighted using CPI disaggregated weights on the period 2003-2011. Black dotted line: price changes related to sales are excluded using a filter allowing for asymmetric V-shaped sales (see description of filters in Appendix), a 5-month window is considered for return to the original price. Gray solid line: price changes related to sales are excluded using INSEE sales flag. 


\section{A.2 Frequency and size of price change - some ro- bustness analysis}

Table D: Frequency and size of price changes 1994-2003 versus 2003-2011

\begin{tabular}{lcccc}
\hline & \multicolumn{2}{c}{$1994-2003$} & \multicolumn{2}{c}{$2003-2011$} \\
& Mean & Median & Mean & Median \\
& & & & \\
\hline & & & & \\
Including sales & & & & \\
Frequency of price changes & 17.7 & 12.8 & 16.5 & 11.6 \\
\% of price increases & 60.0 & 61.8 & 60.0 & 60.0 \\
Size of price increases & 8.9 & 3.7 & 7.5 & 3.0 \\
Size of price decreases & -10.7 & -5.3 & -9.7 & -4.2 \\
\% of small price changes & 12.4 & - & 18.6 & - \\
& & & & \\
Excluding sales & & & & \\
Frequency of price changes & 15.0 & 8.9 & 14.0 & 8.0 \\
\% of price increases & 63.5 & 66.6 & 64.1 & 64.1 \\
Size of price increases & 5.2 & 3.2 & 4.5 & 2.7 \\
Size of price decreases & -5.8 & -3.5 & -4.6 & -2.3 \\
$\%$ of small price changes & 14.6 & - & 22.1 & - \\
& & & & \\
& & & & \\
\% of seasonal sales & 0.7 & - & 0.7 & - \\
\% of promotional discounts & 1.7 & - & 1.7 & - \\
& & & & \\
\hline
\end{tabular}

Note: Frequency of price changes is the weighted proportion of price changes on all price records; Median frequency of price changes are calculated as the weighted median of product average frequencies of price changes; average size of price changes is the average size of price increases (and decreases) among all non-zero price changes (in percentage), the statistics are weighted using CPI disaggregated weights on the period 2003-2011 or on the period 1994-2003; \% of seasonal sales is the weighted proportion of regulated sales among all observations; \% of promotional discounts is the weighted proportion of promotional discounts (excluding seasonal sales) among all observations; \% of small price changes is the proportion of price changes smaller than $1 \%$ among all price changes. Product substitutions are excluded. For the period 1994-2003, prices collected around the euro changeover (between June 2001 and June 2002) were excluded. 
Table E: Frequency and size of price changes: France (2003-2007) - United States (19982005)

\section{Frequency of price changes}

Average size

of price increases
Average size

of price decreases

\section{France United States France United States France United States}

Including energy

Including sales

19.7

24.1

9.9

14.9

$-13.0$

$-18.5$

Excluding sales

16.9

17.1

5.6

9.2

$-8.3$

$-12.0$

Excluding energy

Including sales

13.7

18.3

10.6

15.7

$-13.9$

$-19.7$

Excluding sales

10.7

10.6

5.8

9.4

$-12.6$

Note: Frequency (or size) of price changes are the weighted average frequency (or size) calculated using product level frequencies of price changes. The average size of price changes is computed here in log-differences. Average frequency and size of price changes are first calculated at product level (on the period 1998-2005 for the United States (Nakamura and Steinsson [2010b]) and on the period 2003-2007 for France) and then aggregate using US weight structure to obtain the average frequency and size of price changes. 
Table F: Frequency, average size and standard deviation of price changes over time: some determinants

\begin{tabular}{lcccccc}
\hline & \multicolumn{3}{c}{ Price increases } & \multicolumn{3}{c}{ Price decreases } \\
& Frequency & $\begin{array}{c}\text { Average } \\
\text { size }\end{array}$ & $\begin{array}{c}\text { Standard } \\
\text { deviation } \\
\end{array}$ & & Frequency & Average \\
size & $\begin{array}{c}\text { Standard } \\
\text { deviation }\end{array}$ \\
\hline \multirow{3}{*}{ Post 2008 } & & & & & & \\
Inflation & -0.241 & $0.796^{* * *}$ & $2.114^{* * *}$ & 0.231 & $-1.157^{* * *}$ & $1.132^{* *}$ \\
& $(0.482)$ & $(0.110)$ & $(0.548)$ & $(0.547)$ & $(0.220)$ & $(0.485)$ \\
Unemployment & 0.652 & -0.015 & -0.157 & $-0.477^{*}$ & 0.185 & 0.011 \\
& $(0.452)$ & $(0.109)$ & $(0.305)$ & $(0.285)$ & $(0.142)$ & $(0.142)$ \\
Oil price change & $-0.546^{* * *}$ & $-0.138^{*}$ & 0.070 & $-0.398^{* *}$ & $0.245^{* * *}$ & -0.033 \\
& $(0.203)$ & $(0.081)$ & $(0.215)$ & $(0.183)$ & $(0.083)$ & $(0.116)$ \\
Intercept & 0.005 & -0.002 & $-0.008^{*}$ & -0.007 & $-0.005^{*}$ & 0.003 \\
& $(0.006)$ & $(0.001)$ & $(0.004)$ & $(0.005)$ & $(0.003)$ & $(0.002)$ \\
\hline N observations & $18.539^{* * *}$ & $5.741^{* * *}$ & $5.289^{* *}$ & $11.201^{* * *}$ & $-7.902^{* * *}$ & $6.609^{* * *}$ \\
\hline
\end{tabular}

Note: Frequency of price changes, average size and standard deviation of price changes are monthly weighted statistics, and are calculated using prices excluding sales and substitutions, on the period Aug. 1994 - Feb. 2003 and April 2003 - April 2011. The table reports time-series OLS parameter estimates and standard deviations of estimates in brackets (standard errors are corrected by a Newey-West procedure allowing autocorrelation up to 12 lags). *** significant at $1 \%$, ** significant at $5 \%$, * significant at 10\%. "Post 2008" is a dummy variable equal to one after 2008, "Inflation" is the aggregate inflation rate, "Unemployment" is the unemployment rate in France (source Eurostat), "Oil price change" is the year on year price change of Brent in euros. Month controls and a euro dummy equal to one around the euro changeover are included. 
Table G: Frequency, average size and standard deviation of price changes over time: some determinants

\begin{tabular}{lcccccc}
\hline & \multicolumn{3}{c}{ Price increases } & \multicolumn{3}{c}{ Price decreases } \\
& Frequency & $\begin{array}{c}\text { Average } \\
\text { size }\end{array}$ & $\begin{array}{c}\text { Standard } \\
\text { deviation }\end{array}$ & Frequency & $\begin{array}{c}\text { Average } \\
\text { size }\end{array}$ & $\begin{array}{c}\text { Standard } \\
\text { deviation }\end{array}$ \\
& & & & & & \\
\hline \multirow{3}{*}{ Great Recession } & $-1.381^{*}$ & $0.605^{* * *}$ & $0.822^{*}$ & $1.816^{* * *}$ & $-0.784^{* *}$ & -0.488 \\
& $(0.802)$ & $(0.192)$ & $(0.461)$ & $(0.684)$ & $(0.372)$ & $(0.340)$ \\
Inflation & $2.227^{* *}$ & -0.135 & -0.421 & $4.337^{* * *}$ & $0.353^{* *}$ & -0.067 \\
& $(1.084)$ & $(0.144)$ & $(0.282)$ & $(1.199)$ & $(0.148)$ & $(0.131)$ \\
Unemployment & $-0.652^{* * *}$ & $-0.203^{* *}$ & -0.185 & $-0.244^{*}$ & $0.349^{* * *}$ & $-0.267^{* * *}$ \\
& $(0.229)$ & $(0.089)$ & $(0.198)$ & $(0.144)$ & $(0.101)$ & $(0.094)$ \\
Oil price change & 0.004 & -0.001 & -0.008 & -0.006 & -0.005 & 0.003 \\
& $(0.006)$ & $(0.002)$ & $(0.005)$ & $(0.005)$ & $(0.003)$ & $(0.003)$ \\
Intercept & $19.474^{* * *}$ & $6.657^{* * *}$ & $8.512^{* * *}$ & $9.807^{* * *}$ & $-9.326^{* * *}$ & $9.273^{* * *}$ \\
& $(3.028)$ & $(0.993)$ & $(2.101)$ & $(2.178)$ & $(1.096)$ & $(1.142)$ \\
\hline N observations & 199 & 199 & 199 & 199 & 199 & 199 \\
\hline
\end{tabular}

Note: Frequency of price changes, average size and standard deviation of price changes are monthly weighted statistics, and are calculated using prices excluding sales and substitutions, on the period Aug. 1994 - Feb. 2003 and April 2003 - April 2011. The table reports time-series OLS parameter estimates and standard deviations of estimates in brackets (standard errors are corrected by a Newey-West procedure allowing autocorrelation up to 12 lags). *** significant at $1 \%$, ** significant at $5 \%$, * significant at 10\%. "Great Recession" is a dummy variable equal to 1 when France was in recession, we use the datation of CEPR Euro Area Business Cycle for France (Jan 2008 to June 2009), "Inflation" is the aggregate inflation rate, "Unemployment" is the unemployment rate in France (source Eurostat), "Oil price change" is the year on year price change of Brent in euros. Month controls and a euro dummy equal to one around the euro changeover are included. 


\section{Results excluding product substitutions}

Table H: Frequency of price changes by sector

Food Manufacturing goods
Durables Clothing Other manuf.

\begin{tabular}{|c|c|c|c|c|c|c|}
\hline \multicolumn{7}{|l|}{ Including sales } \\
\hline$\%$ of price increases & 56.7 & 42.7 & 33.4 & 65.1 & 60.7 & 79.8 \\
\hline \multicolumn{7}{|l|}{ Excluding sales } \\
\hline Frequency of price changes & 15.9 & 9.3 & 2.2 & 9.9 & 76.9 & 6.7 \\
\hline$\%$ of price increases & 58.6 & 42.8 & 60.2 & 69.2 & 60.8 & 80.9 \\
\hline
\end{tabular}

Note: Frequency of price changes is the weighted proportion of price changes on all price records (excluding product substitutions). 
Table I: Size of price changes by sector

\begin{tabular}{|c|c|c|c|c|c|c|c|c|}
\hline & \multicolumn{4}{|c|}{ Price increases } & \multicolumn{4}{|c|}{ Price decreases } \\
\hline & Mean & Q1 & Median & Q3 & Mean & Q1 & Median & Q3 \\
\hline \multicolumn{9}{|l|}{ Including sales } \\
\hline Food & 9.7 & 2.0 & 4.4 & 10.1 & -8.8 & -11.8 & -4.9 & -1.9 \\
\hline \multicolumn{9}{|l|}{ Manufacturing sector } \\
\hline Durables & 15.9 & 3.6 & 10.3 & 22.2 & -13.4 & -19.2 & -11.1 & -6.1 \\
\hline Clothing & 50.5 & 17.6 & 42.9 & 66.9 & -34.1 & -50.0 & -30.1 & -22.5 \\
\hline Other manuf. & 9.6 & 1.7 & 3.5 & 9.1 & -12.0 & -19.6 & -7.0 & -2.1 \\
\hline Energy & 3.8 & 1.7 & 3.0 & 5.0 & -3.9 & -5.1 & -2.9 & -1.5 \\
\hline Services & 7.2 & 2.0 & 3.6 & 7.7 & -11.7 & -16.7 & -8.8 & -3.3 \\
\hline Total & 8.9 & 1.9 & 3.7 & 7.7 & -10.7 & -14.3 & -5.3 & -2.0 \\
\hline \multicolumn{9}{|l|}{ Excluding sales } \\
\hline Food & 5.6 & 1.7 & 3.5 & 6.8 & -5.5 & -7.2 & -3.4 & -1.5 \\
\hline \multicolumn{9}{|l|}{ Manufacturing sector } \\
\hline Durables & 7.9 & 1.8 & 5.0 & 10.4 & -9.4 & -13.1 & -8.0 & -4.0 \\
\hline Clothing & 10.6 & 1.8 & 4.7 & 11.1 & -15.4 & -24.1 & -10.8 & -2.5 \\
\hline Other manuf. & 5.5 & 1.5 & 3.0 & 6.0 & -7.1 & -9.5 & -3.9 & -1.4 \\
\hline Energy & 3.8 & 1.7 & 3.0 & 5.0 & -3.8 & -5.1 & -2.9 & -1.5 \\
\hline Services & 6.7 & 2.0 & 3.6 & 7.2 & -10.8 & -15.3 & -7.9 & -2.8 \\
\hline Total & 5.2 & 1.7 & 3.2 & 5.9 & -5.8 & -7.4 & -3.5 & -1.6 \\
\hline
\end{tabular}

Note: The statistics on the size of price changes are all weighted using CPI disaggregated weights. Individual sizes of price changes are here calculated in percentage, and only non-zero price changes are considered (excluding product substitutions). 
Figure C: Monthly inflation including or excluding product replacements

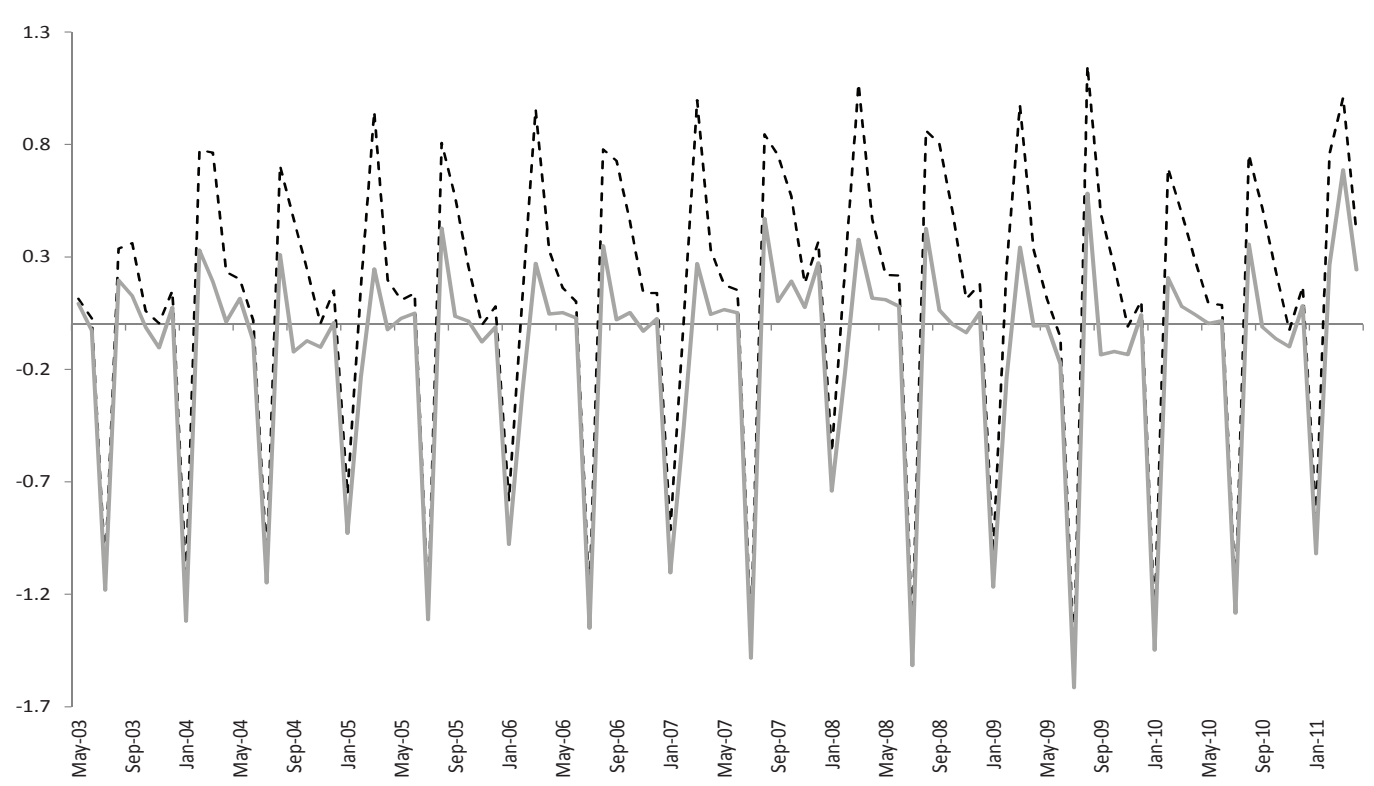

(a) Including sales

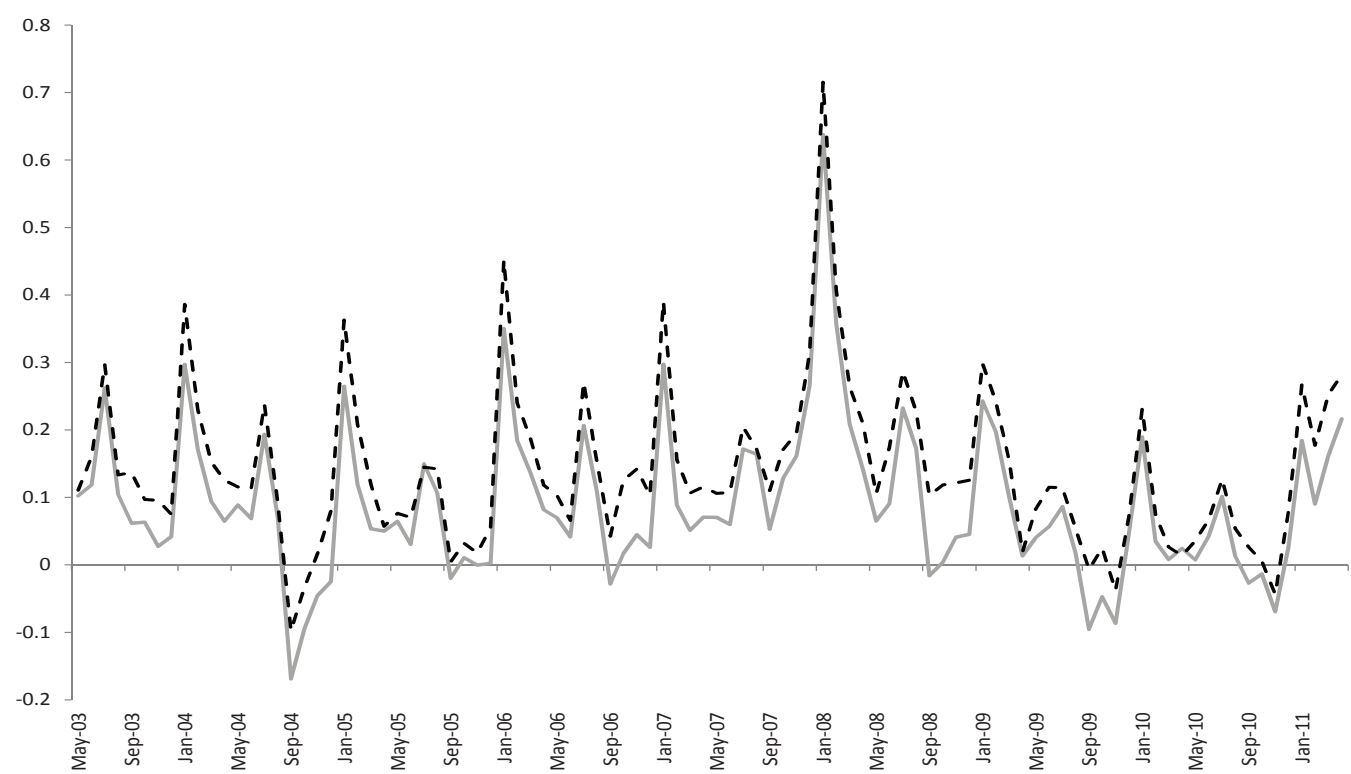

(b) Excluding sales

Note: Gray solid line: monthly rate of inflation (excluding energy), excluding price changes due to replacements. Black dashed line: monthly rate of inflation (excluding energy), including price changes due to replacements. 


\section{A.3 More results on the incidence of sales and prod- uct substitutions}

Table J: Size of price changes - Seasonal sales and temporary promotions

\begin{tabular}{lcc}
\hline & $\begin{array}{c}\text { Seasonal } \\
\text { sales }\end{array}$ & $\begin{array}{c}\text { Temporary } \\
\text { promotions }\end{array}$ \\
& & \\
\hline Price decreases & & \\
Mean & -34.9 & -20.3 \\
Std & 8.4 & 7.8 \\
Lower quartile & -50.0 & -28.5 \\
Median & -30.1 & -18.2 \\
Higher quartile & -22.8 & -10.2 \\
& & \\
Price increases & & \\
Mean & 67.3 & 35.3 \\
Std & 31.6 & 21.6 \\
Lower quartile & 100.0 & 13.0 \\
Median & 48.2 & 25.0 \\
Higher quartile & 26.9 & 42.9 \\
& & \\
\hline
\end{tabular}

Note: The statistics on the size of price changes are all weighted using CPI disaggregated weights on the period 2003-2011. Individual sizes of price changes are here calculated in percentage, and only non-zero price changes are considered (including substitutions). The size of price decreases is calculated when prices are on sales while the size of price increases is calculated just after the end of sales. 
Table K: Seasonality of promotions and sales

Proportion of promotional discounts (in \%)
Proportion of seasonal sales (in \%)

\section{Total Food Manufacturing goods Total Food Manufacturing goods} Durables Clothing Other Durables Clothing Other

\begin{tabular}{lcccccccccc}
\hline & & & & & & & & & \\
January & 2.3 & 3.2 & 2.9 & 1.0 & 1.6 & 4.7 & 0.0 & 4.6 & 29.2 & 1.0 \\
February & 2.7 & 3.1 & 3.5 & 3.4 & 1.6 & 2.6 & 0.0 & 2.7 & 16.6 & 0.7 \\
March & 3.0 & 3.1 & 5.1 & 3.5 & 1.9 & 0.0 & 0.0 & 0.0 & 0.1 & 0.0 \\
April & 2.9 & 3.1 & 5.1 & 3.4 & 1.8 & 0.0 & 0.0 & 0.1 & 0.1 & 0.0 \\
May & 2.6 & 2.8 & 4.5 & 3.1 & 1.5 & 0.0 & 0.0 & 0.0 & 0.1 & 0.0 \\
June & 2.6 & 3.0 & 4.4 & 1.8 & 1.6 & 0.2 & 0.0 & 0.3 & 1.3 & 0.0 \\
july & 2.1 & 2.7 & 3.2 & 0.7 & 1.6 & 5.2 & 0.0 & 5.5 & 35.3 & 1.0 \\
August & 2.8 & 2.4 & 4.1 & 6.7 & 1.6 & 0.9 & 0.0 & 0.9 & 6.5 & 0.2 \\
September & 2.8 & 3.1 & 5.1 & 2.6 & 1.7 & 0.0 & 0.0 & 0.0 & 0.1 & 0.0 \\
October & 2.8 & 3.0 & 5.0 & 2.6 & 1.7 & 0.0 & 0.0 & 0.1 & 0.1 & 0.0 \\
November & 3.0 & 3.0 & 5.4 & 3.5 & 1.9 & 0.0 & 0.0 & 0.0 & 0.1 & 0.0 \\
December & 2.9 & 3.3 & 5.3 & 2.3 & 1.9 & 0.0 & 0.0 & 0.0 & 0.0 & 0.0 \\
& & & & & & & & & & \\
\hline
\end{tabular}

Note: \% of seasonal sales is the weighted proportion of regulated sales among all observations; \% of promotional discounts is the weighted proportion of temporary promotional discounts (excluding seasonal sales) among all observations. Results concerning services and energy are not reported since sales are quite rare int those sectors. 
Table L: Seasonality of product substitutions

\begin{tabular}{|c|c|c|c|c|c|}
\hline & \multicolumn{5}{|c|}{$\begin{array}{l}\text { Proportion of product substitutions } \\
\text { (in \%) }\end{array}$} \\
\hline & \multirow[t]{2}{*}{ Total } & \multirow[t]{2}{*}{ Food } & \multicolumn{3}{|c|}{ Manufacturing goods } \\
\hline & & & Durables & Clothing & Other manuf. \\
\hline January & 4.5 & 2.4 & 10.1 & 5.5 & 4.5 \\
\hline February & 6.5 & 2.3 & 11.2 & 20.1 & 4.7 \\
\hline March & 7.9 & 2.2 & 10.1 & 31.6 & 4.5 \\
\hline April & 6.3 & 2.2 & 9.7 & 19.4 & 4.4 \\
\hline May & 5.1 & 2.1 & 9.4 & 13.2 & 3.7 \\
\hline June & 4.8 & 2.2 & 9.8 & 10.2 & 3.7 \\
\hline July & 3.7 & 2.0 & 8.3 & 3.9 & 3.5 \\
\hline August & 5.3 & 1.7 & 8.9 & 19.1 & 3.7 \\
\hline September & 8.4 & 2.2 & 11.5 & 35.7 & 4.6 \\
\hline October & 6.9 & 2.4 & 10.4 & 21.8 & 4.3 \\
\hline November & 5.6 & 2.3 & 9.7 & 12.8 & 4.7 \\
\hline December & 4.6 & 2.2 & 8.5 & 9.2 & 3.8 \\
\hline
\end{tabular}

Note: \% of product substitutions is the weighted proportion of product replacements among all price records. Results concerning services and energy are not reported since substitutions are quite rare. 
Figure D: Seasonality of the frequency of price changes (excluding sales) - by sector

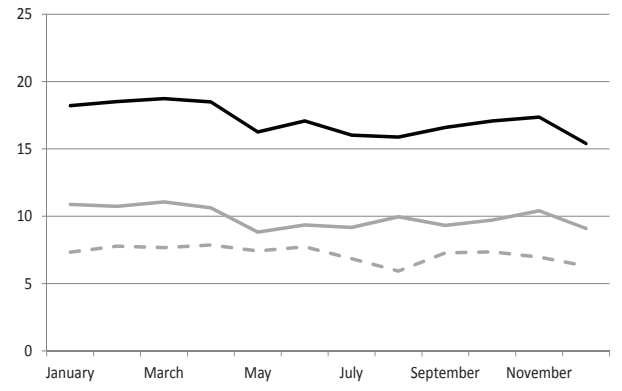

(a) Food

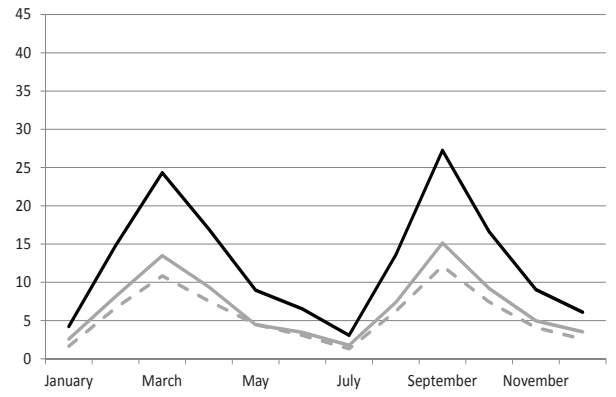

(c) Clothing

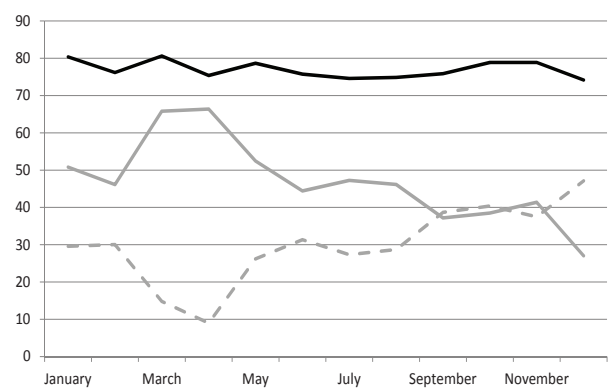

(e) Energy

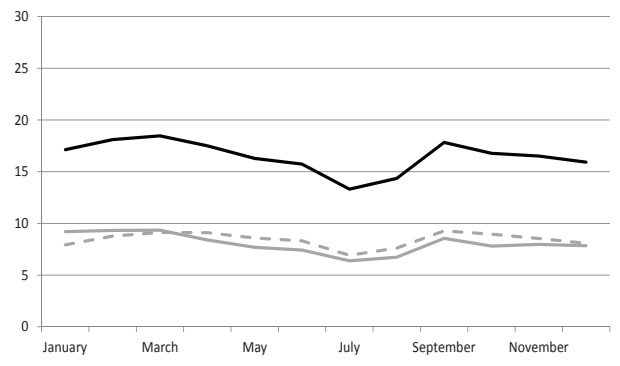

(b) Durables

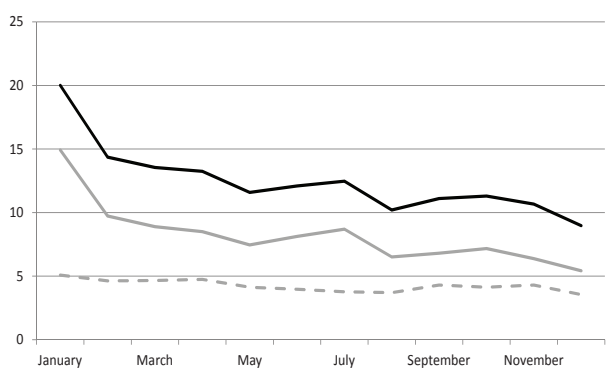

(d) Other Manuf.

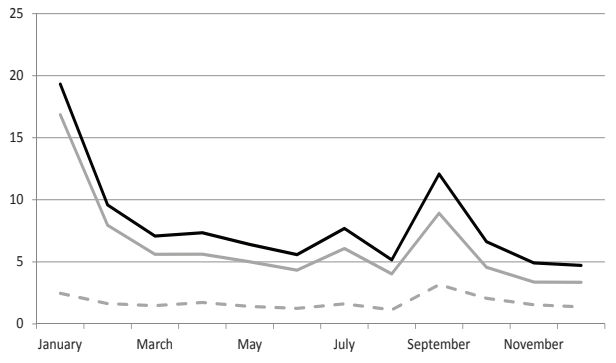

(f) Services

Note: Price changes related to product replacements are considered as price changes and price changes related to sales are excluded. Black solid line: frequency of price changes, gray solid line: frequency of price increases and gray dashed line: frequency of price decreases 
Figure E: Frequency of sales and temporary promotions over time

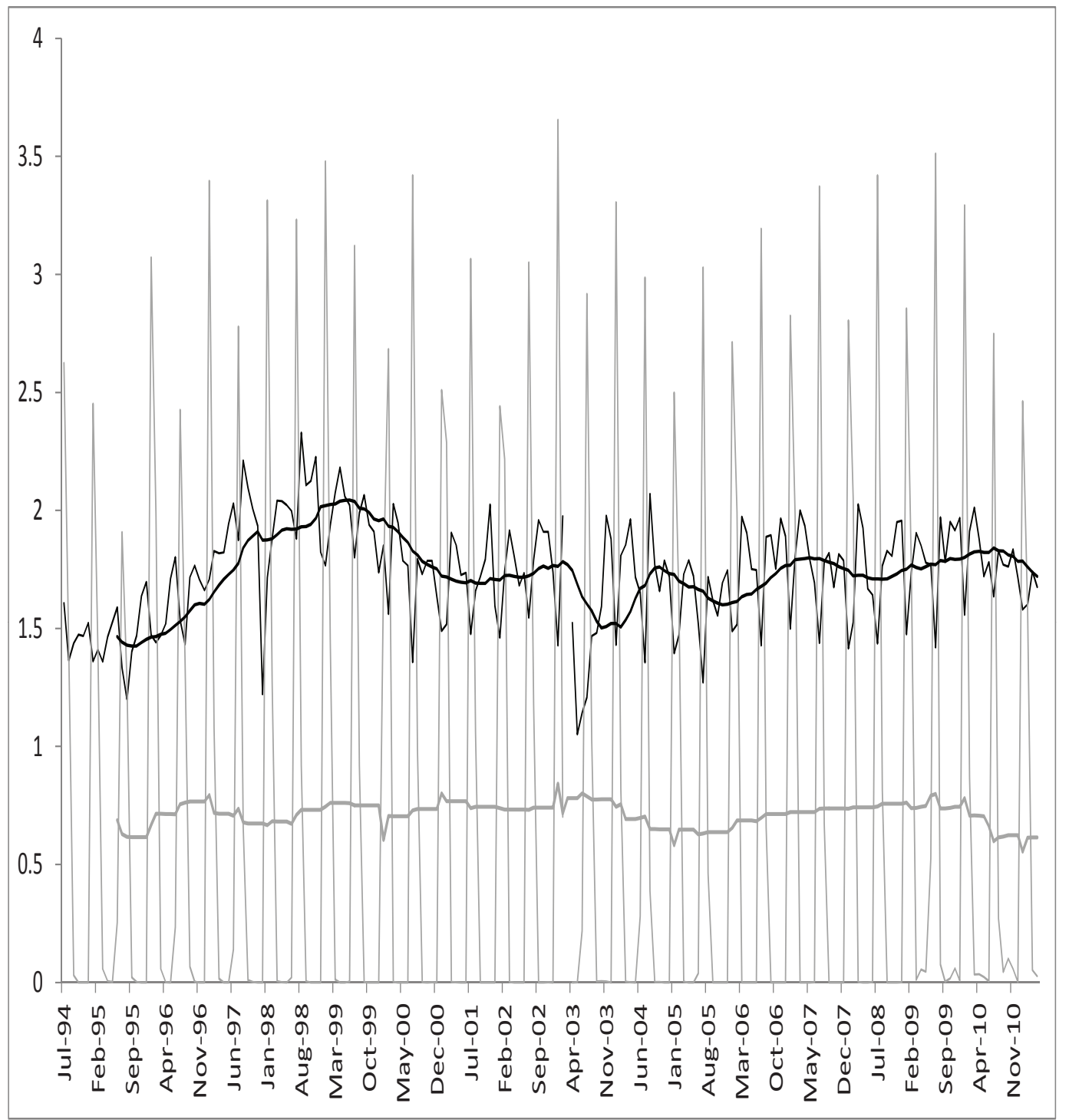

Note: Gray lines: Monthly weighted frequency of seasonal sales and its moving average over 12 months. Black lines : Monthly weighted frequency of promotions and its moving average over 12 months. Numbers for the period July 1994-February 2003 are coming from results of Baudry et al. [2007], January 2002 is excluded. 


\section{A.4 Econometric results: Robustness}

Table M: Probability and size of price changes on inflation, unemployment, oil prices and recession

\begin{tabular}{lcccc}
\hline & \multicolumn{2}{c}{ Price increases } & \multicolumn{2}{c}{ Price decreases } \\
& & & \\
& Probability & Size & Probability & Size \\
& & & & \\
\hline & & & & \\
Cumulative inflation & $0.309^{* * *}$ & $0.078^{* * *}$ & $-0.194^{* * *}$ & $0.249^{* * *}$ \\
& $(0.004)$ & $(0.002)$ & $(0.003)$ & $(0.013)$ \\
Unemployment & $-1.012^{* * *}$ & $-1.012^{* * *}$ & $0.372^{* * *}$ & $-0.192^{* *}$ \\
& $(0.038)$ & $(0.010)$ & $(0.032)$ & $(0.083$ \\
Great Recession & 0.049 & $0.036^{* *}$ & $-0.361^{* * *}$ & $-0.585^{* * *}$ \\
& $(0.054)$ & $(0.015)$ & $(0.047)$ & $(0.106)$ \\
Cumulative oil & $-0.014^{* * *}$ & $-0.003^{* * *}$ & $-0.018^{* * *}$ & $-0.017^{* * *}$ \\
price change & $(0.000)$ & $(0.000)$ & $(0.000)$ & $(0.001)$ \\
\hline N observations & $8,022,198$ & 682,295 & $8,022,198$ & 477,654 \\
\hline
\end{tabular}

Note: The sample excludes prices of the energy sector and consist of price changes excluding sales and including substitutions. The table reports marginal effects obtained from the estimation of Tobit models. "Cumulative inflation" is the cumulative inflation rate since the last price change in a given outlet $i$ (4-digit product level), inflation rate is computed using individual price data excluding sales and including substitutions. "Unemployment" is the unemployment rate in France (source Eurostat). "Great Recession" is a dummy variable equal to 1 when France was in recession, we use the datation of CEPR Euro Area Business Cycle for France (Jan 2008 to June 2009). "Cumulative oil price change" is the cumulative oil log-price change since the last price change in a given outlet $i$, oil price is the Brent (in euros) price (source INSEE). Year, month and product (5-digit product level) controls are included. $* * *$ significant at $1 \%,{ }^{* *}$ significant at $5 \%, *$ significant at $10 \%$. Standard deviations of estimates are reported in brackets. 
Table N: Probability and size of price changes on inflation, unemployment, oil price, and recession - only services

\begin{tabular}{lcccc}
\hline & \multicolumn{2}{c}{ Price increases } & \multicolumn{2}{c}{ Price increases } \\
& & & \\
& Probability & Size & Probability & Size \\
& & & & \\
\hline & & & & \\
Cumulative inflation & $0.319^{* * *}$ & $0.140^{* * *}$ & $0.345^{* * *}$ & $0.146^{* * *}$ \\
& $(0.006)$ & $(0.006)$ & $(0.007)$ & $(0.006)$ \\
Unemployment & $-0.448^{* * *}$ & $-0.106^{* * *}$ & $-0.513^{* * *}$ & $-0.118^{* * *}$ \\
& $(0.075)$ & $(0.031)$ & $(0.074)$ & $(0.032$ \\
Great Recession & $1.634^{* * *}$ & $0.407^{* * *}$ & $1.306^{* * *}$ & $0.334^{* * *}$ \\
& $(0.108)$ & $(0.050)$ & $(0.112)$ & $(0.051)$ \\
Cumulative oil & & & $-0.009^{* * *}$ & $-0.002^{* * *}$ \\
price change & & & $(0.001)$ & $(0.000)$ \\
\hline N observations & $1,393,799$ & 83,250 & $1,393,799$ & 83,250 \\
\hline
\end{tabular}

Note: The sample only includes prices of services and consist of price changes excluding sales and including product substitutions. The table reports marginal effects obtained from the estimation of Tobit models. "Cum. inflation" is the cumulative inflation rate since the last price change in a given outlet $i$ (4-digit product level), inflation rate is computed using individual price data excluding sales and including substitutions. "Unemployment" is the unemployment rate in France (source Eurostat). "Great Recession" is a dummy variable equal to 1 when France was in recession, we use the datation of CEPR Euro Area Business Cycle for France (Jan 2008 to June 2009). "Cumulative oil price change" is the cumulative oil log-price change since the last price change in a given outlet $i$, oil price is the Brent (in euros) price (source INSEE). Year, month and product (5-digit product level) controls are included. *** significant at $1 \%, * *$ significant at $5 \%, *$ significant at $10 \%$. Standard deviations of estimates are reported in brackets. 